\title{
Chiral Phase-Transfer Catalysts with Hydrogen Bond: A Powerful Tool in the Asymmetric Synthesis
}

\author{
Hongyu Wang \\ College of Chemistry, Chemical Engineering and Materials Science, Key Laboratory of Molecular and Nano \\ Probes, Ministry of Education, Collaborative Innovation Center of Functional Probes for Chemical Imaging in \\ Universities of Shandong, Institute of Molecular and Nano Science, Shandong Normal University, \\ Jinan 250014, China; wanghongyu@sdnu.edu.cn
}

Received: 20 January 2019; Accepted: 4 March 2019; Published: 7 March 2019

check for updates

\begin{abstract}
Asymmetric phase-transfer catalysis has been widely applied into organic synthesis for efficiently creating chiral functional molecules. In the past decades, chiral phase-transfer catalysts with proton donating groups are emerging as an extremely significant strategy in the design of novel catalysts, and a large number of enantioselective reactions have been developed. In particular, the proton donating groups including phenol, amide, and (thio)-urea exhibited unique properties for cooperating with the phase-transfer catalysts, and great advances on this field have been made in the past few years. This review summarizes the seminal works on the design, synthesis, and applications of chiral phase-transfer catalysts with strong hydrogen bonding interactions.
\end{abstract}

Keywords: phase-transfer catalysis; asymmetric synthesis; hydrogen bond; bifunctional catalysts; asymmetric phase-transfer catalysis

\section{Introduction}

Since Starks firstly introduced the term "phase-transfer catalysis" in 1971 [1], it has been widely applied in organic reactions in different immiscible phases. Moreover, asymmetric phase-transfer catalysis, as an important strategy for preparing chiral functional molecules, has also attracted chemists' attentions, and thus many novel organic reactions have been achieved with highly enantioselectivities, while utilizing structurally well-defined chiral phase-transfer catalysts [2]. Therefore, the design and synthesis of efficient chiral quaternary onium salt catalysts become an attractive area, as it features mild reaction conditions, environmentally benign reagents, and low catalyst loading.

In the past decades, the phase-transfer catalysts that are based on the skeletons of cinchona alkaloids, and chiral binaphthyls were emerging as the most successful examples, including the quaternary ammonium salts and quaternary phosphonium salts (Scheme 1a) [3-14]. However, many efforts were poured on the design of chiral phase-transfer catalysts via the modifications of the substitutes on the onium salts, other interaction forces did not attract enough attention over the past decades. Recently, the strategy via introducing secondary interactions for the design of the bifunctional catalysts achieved wide application in asymmetric reactions [15]. Hydrogen bond, as a significant interaction force, widely exists in biomacromolecules, such as proteins and nucleic acids, which was also successfully applied in the design and synthesis of novel catalysts, especially for the organocatalysts [16]. It has also attracted chemists' attention in the design of efficient phase-transfer catalysts, which has become a hot topic, especially in the past few years (Scheme 1b). Up to now, many phase transfer catalysts have been successfully developed utilizing amide and (thio)-urea. Accordingly, this review will cover the design, synthesis, and applications of chiral phase-transfer catalysts with proton donating groups in order to accelerate the development of this area. 
a) Well studied:

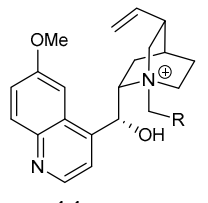

$1-1$

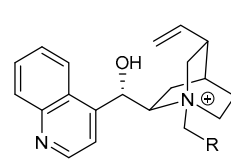

$1-2$

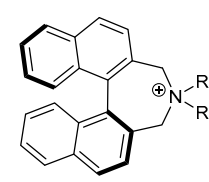

1-3

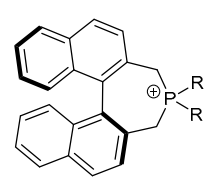

$1-4$

b) New strategy for the novel phase transfer catalysts

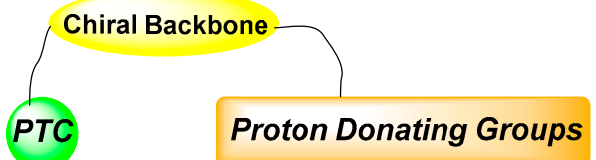

PTC : Phanse Transfer Catalyst

Scheme 1. Chiral phase-transfer catalysts.

\section{Early Examples}

As a pioneering example of chiral quaternary ammonium salt with proton donating groups, Fiaud developed an interesting example that was derived from the Ephedrine in 1975 (Scheme 2) [17]. Although the ee values were not determined, it is nevertheless a valuable example of a chiral quaternary ammonium salt with a hydrogen bond.

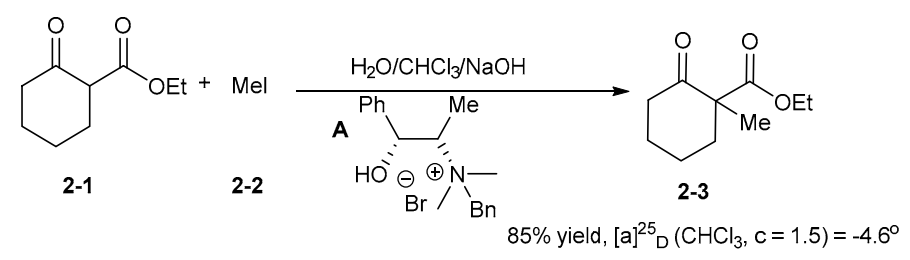

Scheme 2. Chiral phase-transfer catalyst derived from Ephedrine.

After that, quaternary ammonium salts with a hydroxyl group derived from cinchona alkaloids have been widely applied into various asymmetric reactions, and the hydroxyl group presented a significant role in improving the enantioselectivities of these organic reactions. Palomo and co-workers interpreted the importance of the hydrogen bond based on the mechanistic experiments and kinetic studies [18]. The interaction between the nitro group and the catalyst' $\mathrm{OH}$ group is more favorable, and the rigidity and stability of the complex might be one of the reasons for the high enantioselectivity of the reaction (Scheme 3). Catalysts will not be summarized in this context, because a few reviews have focused on these catalysts.

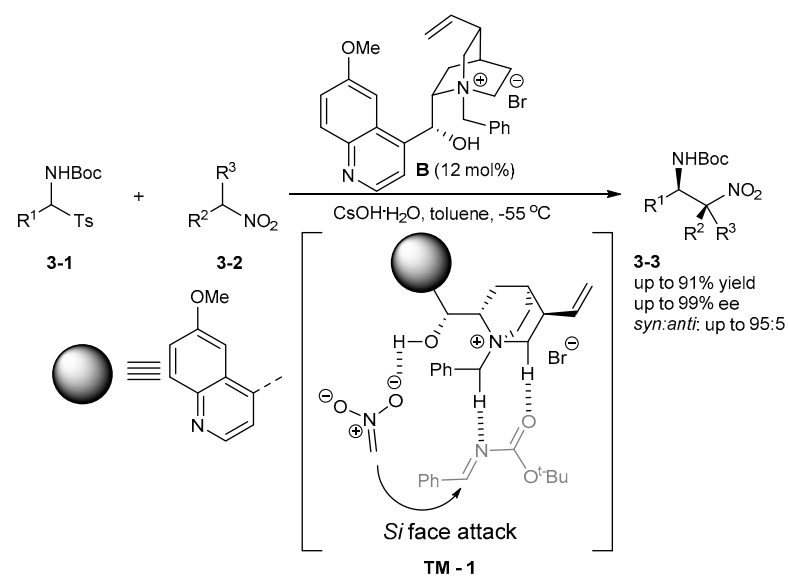

Scheme 3. Asymmetric aza-Henry reactions. 


\section{Bifunctional Phase-Transfer catalysts derived from Cinchona alkaloids}

Inspired by the bifunctional Brønsted bases with proton donating groups, which have been successfully applied into building chiral compounds over the past decades, chiral phase transfer catalysts with hydrogen donating groups have got attained attentions from chemists. Lassaletta and co-workers firstly reported a new family of thiourea/quaternary ammonium salts in 2010, which were applied for the asymmetric cyanosilylation of nitroalkenes. The hydrogen bonding interaction between nitroalkene and thiourea plays an important role in the control of enantioselectivity [19]. After that, Dixon's group reported the phase-transfer catalysts with an activated $\mathrm{N}-\mathrm{H}$ group through introducing amide and urea groups into quaternary ammonium salts in 2012 [20], which could efficiently catalyze the asymmetric aza-Henry reactions with high yields and enantioselectivities under the optimal conditions. As shown in Scheme 4, the quaternary ammonium salt with urea group proved to be the best one for the reaction, which illustrated the importance of the proton donating groups.
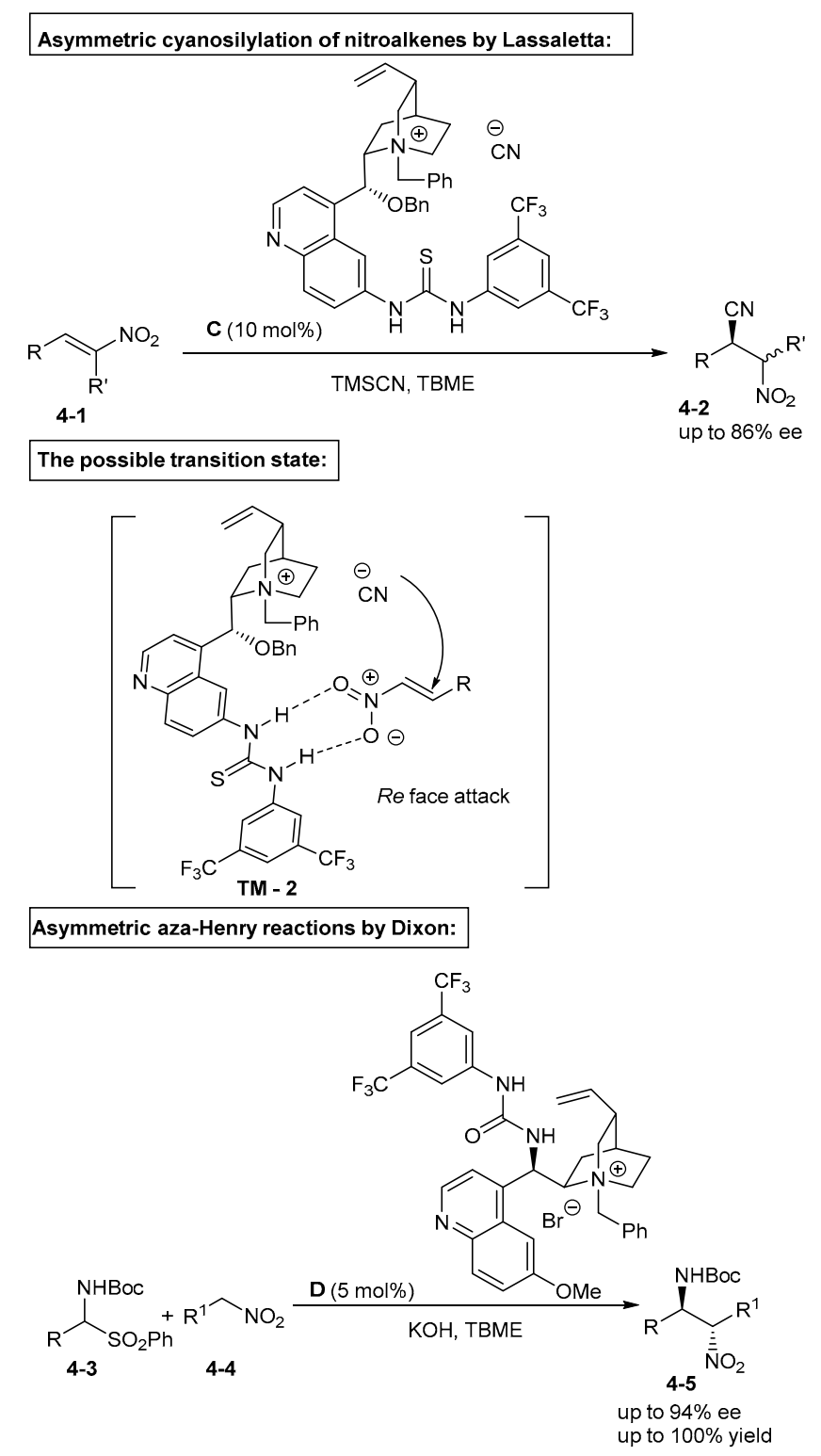

Scheme 4. Insert hydrogen donating groups into cinchona alkaloids for asymmetric aza-Henry reactions.

In 2013, Smith's group reported an interesting asymmetric 5-endo-dig cyclization reaction [21]. Many quaternary-substituted indolenines were generated with high enantioselectivities and it yields 
utilizing $\alpha$-cyanocarbanions and isonitriles (Scheme 5). In particular, enantioenriched indolenines can be functionalized by various nucleophilic species to furnish complex indoline frameworks.

Enantioselective synthesis of quaternary-substituted indolenines:
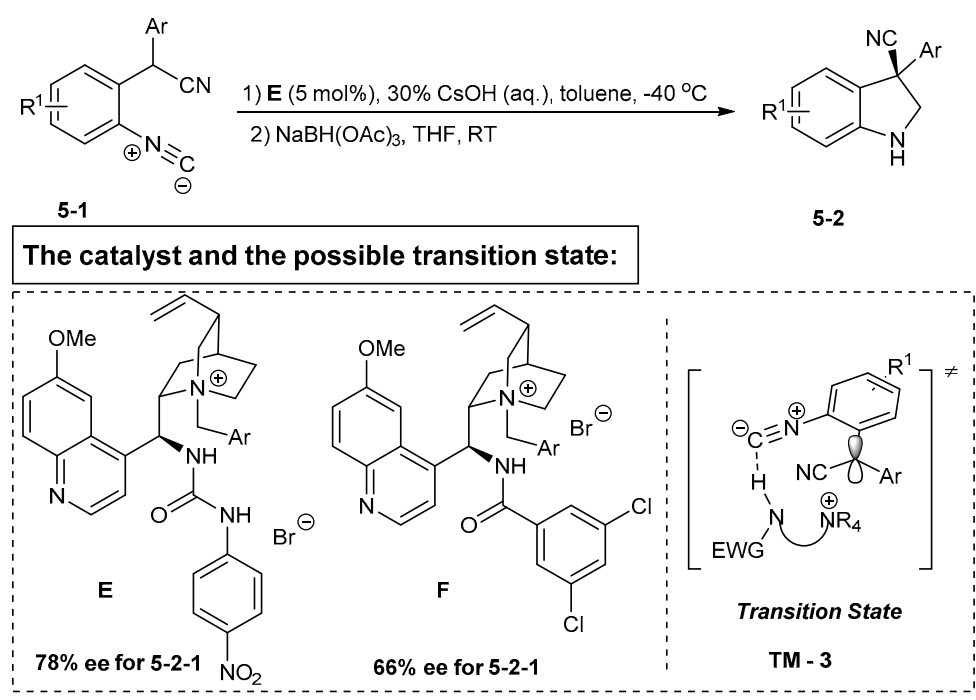

Selected examples:<smiles>N#C[C@]1(c2ccccc2)CNc2ccc(Cl)cc21</smiles><smiles>N#C[C@]1(c2cccc(Br)c2)CNc2ccc(Cl)cc21</smiles><smiles>N#C[C@]1(c2cccs2)CNc2ccc(Cl)cc21</smiles><smiles>Cc1ccc2c(c1)NC[C@]2(N)c1ccc2ccccc2c1</smiles>

Scheme 5. 5-endo-dig cyclization reaction for indolenines.

Due to the high nucleophilic property of " $S$ " atom, the alkylation reaction of the thiourea group is processed easily at a high temperature using chloralkanes. Duan and co-workers developed another method for synthesizing quaternary ammonium salt with the thiourea group (Scheme 6) [22], a high yield of the desired catalyst can be obtained under the optimal conditions. Notably, these salts can efficiently catalyze the asymmetric aza-Henry reactions between ketoimines and nitromethanes. After the further examination of the reaction conditions, up to $93 \%$ ee can be obtained. 


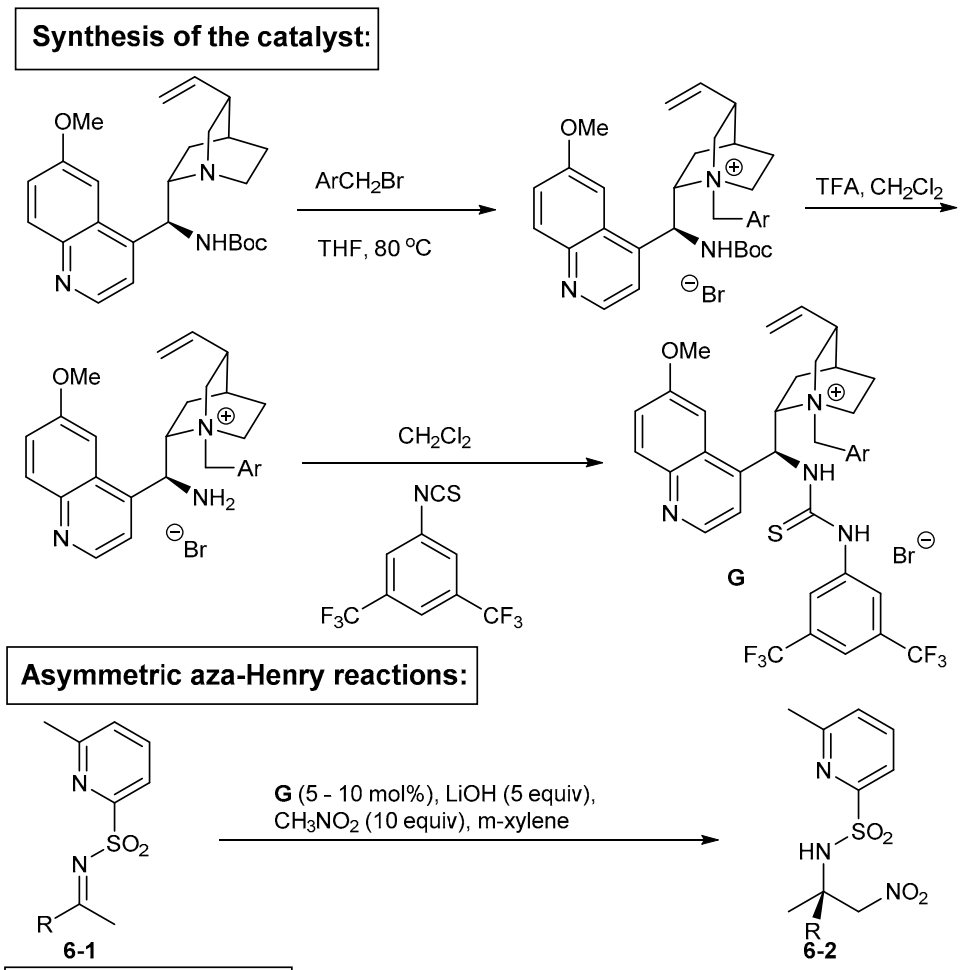

Selected examples:
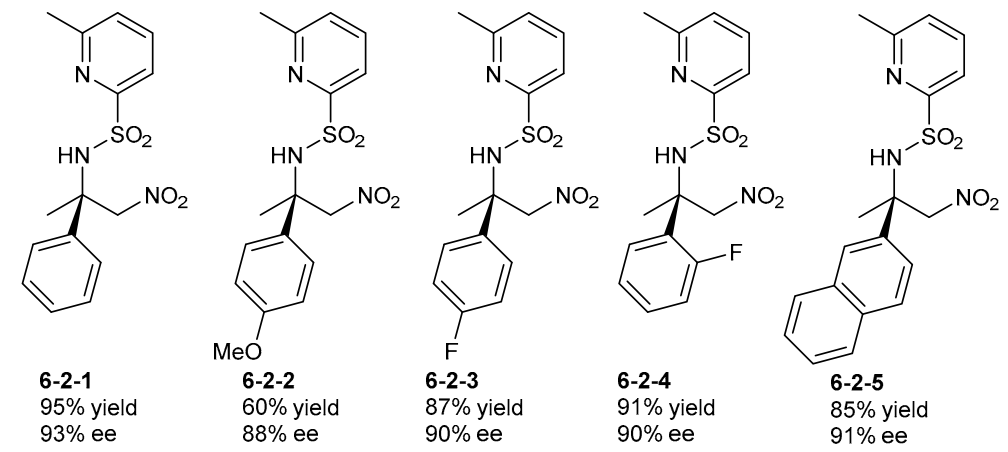

Scheme 6. Asymmetric Henry reactions of ketoimines.

Connon and co-workers also reported the new quaternary ammonium salts with square amide for the kinetic resolution of 2-oxindole-derived enolates (Scheme 7) [23]. Under the optimized conditions, the benzylated, allylated, and propargylated 2-oxindole units can be effectively furnished with high yield and excellent enantioslectivities. Moreover, the optimization studies demonstrated that the squaramide-based hydrogen-bond and chiral ammonium ion were significant factors in the improvement of the enantioselectivities. Accordingly, this strategy by installing proton donating groups into the PTC (phase transfer catalyst) is important in the design of new asymmetric reactions.

In 2014, Duan's group firstly introduced multiple hydrogen bonds into the chiral PTC derived from cinchona alkaloids, as shown in Scheme 8 [24]. The new family of bifunctional catalysts have been successfully applied to the nitro-Minnich reactions with a broad substrate scope. Notably, both enantiomers of the products can be obtained by modifying the chiral backbones of the catalysts that were derived from pseudo-enantiomers (Scheme 8, A and B). Two control experiments illustrated the key role of the multiple hydrogen bonding donors for improving the enantioselectivities. Under the optimized conditions, the methylated catalyst and the tertiary amine catalyst were not suitable for the asymmetric nitro-Mannich reaction, and low enantioselectivity and yield were obtained. 
Duan and co-workers also reported the enantioselective nitro-Mannich reaction of $\alpha$-aryl nitromethanes with amidosulfones catalyzed by these catalysts [25]. Under the optimized conditions, various substituent groups on the benzene ring were tolerated with high ees and yields (Scheme 9). Control experiments revealed the important role of the H-bond interaction on the chiral phase transfer catalysts.

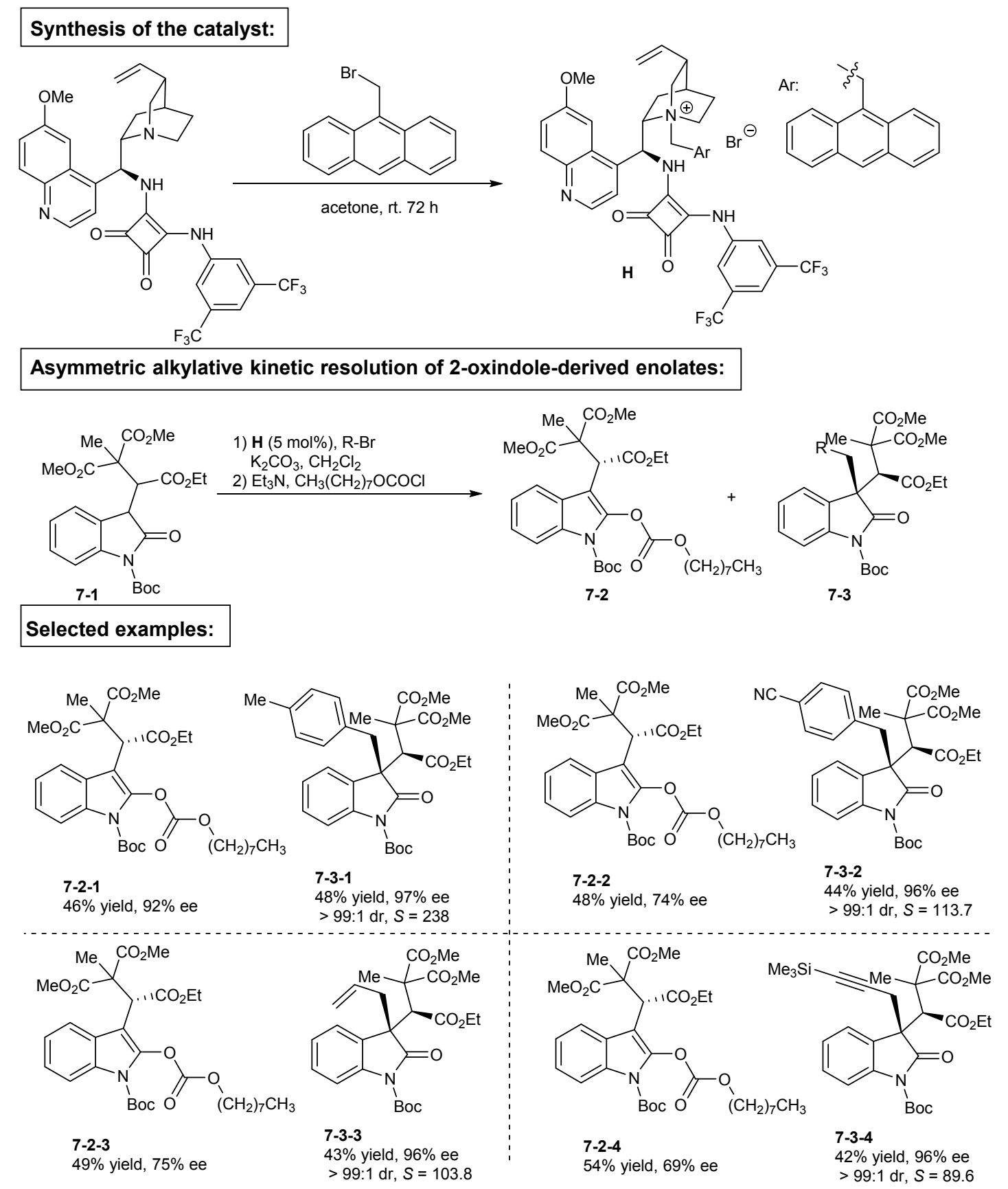

Scheme 7. Chiral phase-transfer catalysts with square amide. 
Synthesis of the catalyst:

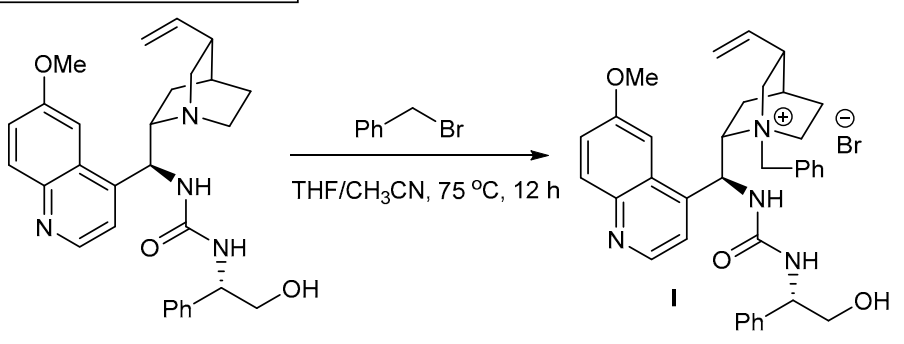<smiles>C=CC1CC2CCN1C([C@H](NC(=O)N[C@H](CO)c1ccccc1)c1ccnc3ccc(OC)cc13)C2</smiles>

Asymmetric aza-Henry reactions:

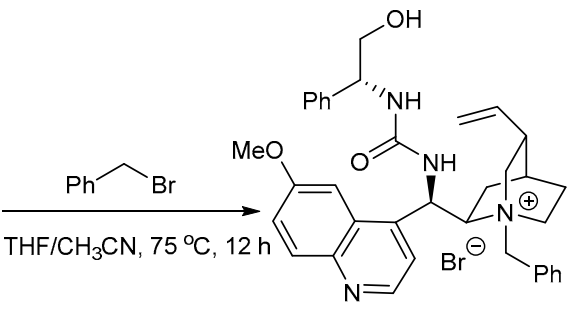

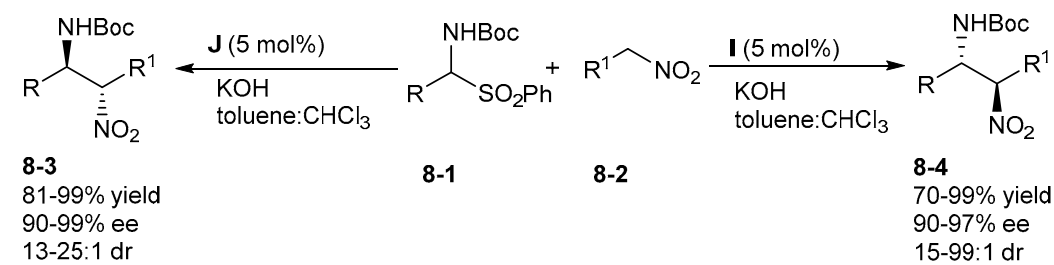

Control experiments:
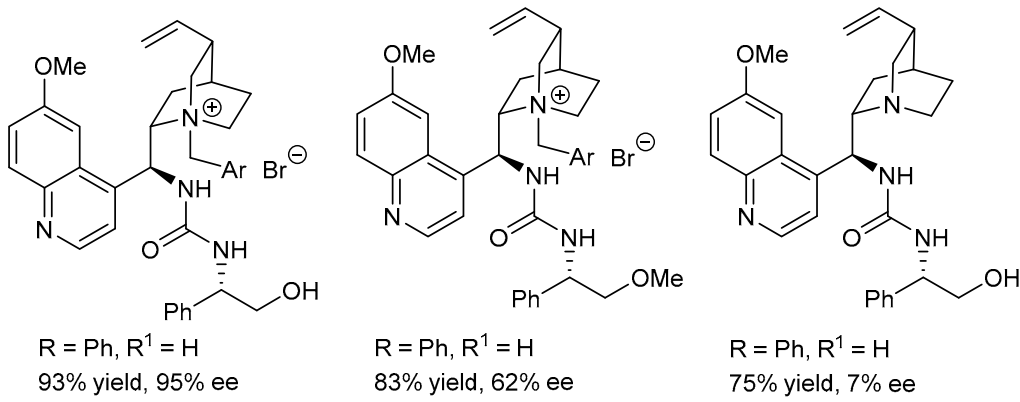

Scheme 8. Multifunctional quaternary ammonium salts for asymmetric aza-Henry reactions.

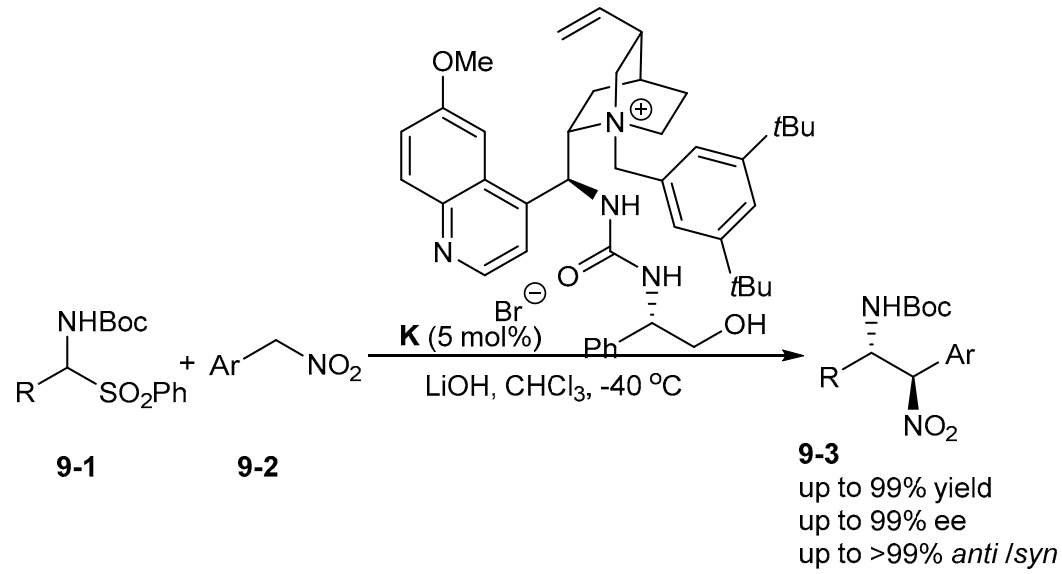

Scheme 9. Enantioselective nitro-Mannich reaction of $\alpha$-aryl nitromethanes. 


\section{Bifunctional Phase-Transfer catalysts derived from Binaphthyl}

Little progress has been made utilizing quaternary phosphonium salts as the phase-transfer catalysts in the past decades, due to the ready elimination of quaternary phosphonium salts under the basic conditions. In 2013, Maruoka's group independently reported a new family of bifunctional quaternary phosphonium salts based on the commercial phosphines (Scheme 10) [26]. These catalysts can be easily prepared via the alkylation of the chiral phosphines with benzyl halides, and these catalysts, under neutral conditions, successfully realized the asymmetric Michael addition reactions between the 3-aryl oxindoles and activated olefins.

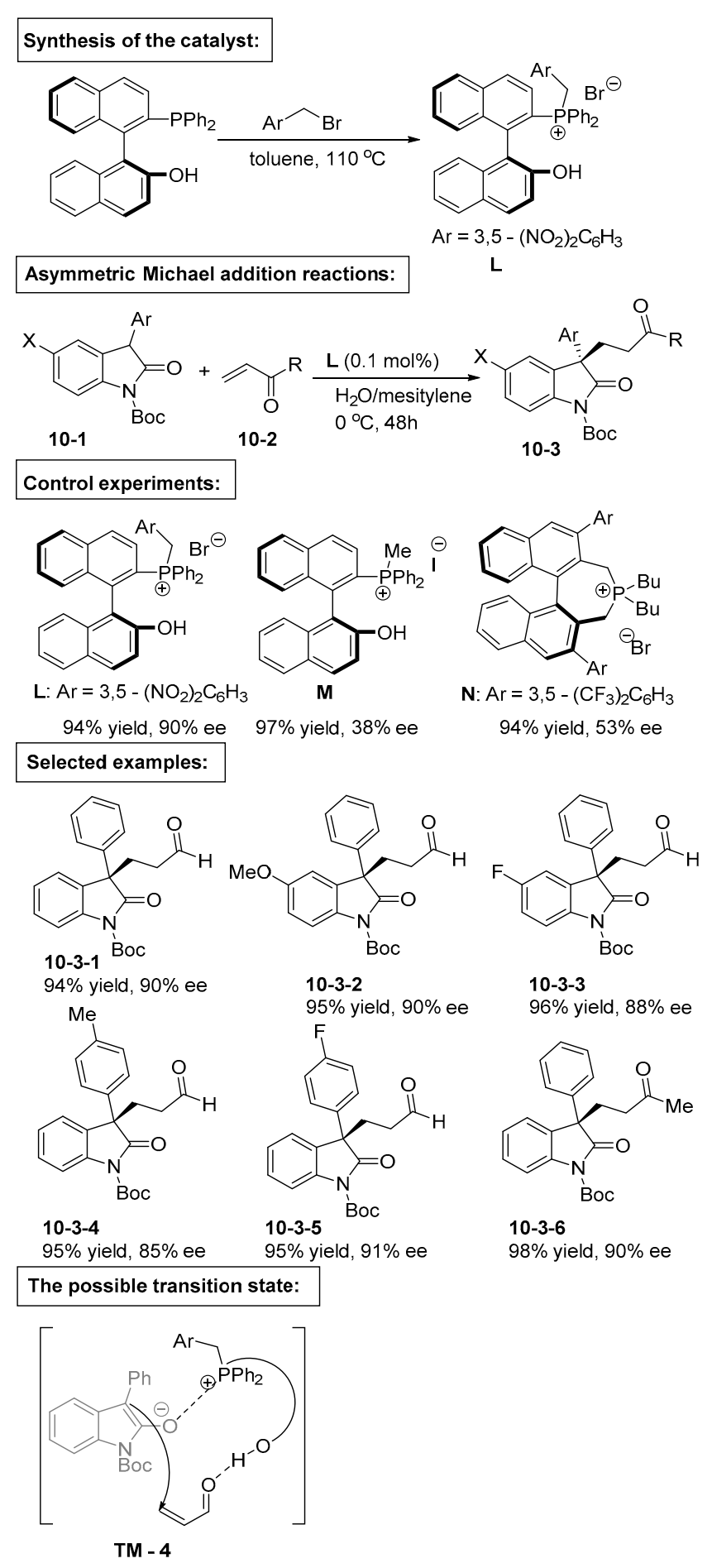

Scheme 10. Chiral quaternary phosphonium salts with hydroxyl group. 
When compared to the hydroxyl group, the amide group exhibits much stronger hydrogen bonding interaction, and it presents in numerous bifunctional catalysts for improving enantioslectivities. Maruoka and co-workers succeeded in applying the bifunctional quaternary phosphonium salt with the amide moiety into the enantioslective sulfenylation and chlorination of $\beta$-ketoesters (Scheme 11) [27]. Based on the control experiments, the fine-tuning of the amide group and the phosphonium centre of the catalyst can furnish the corresponding products with high enantioselectivities.

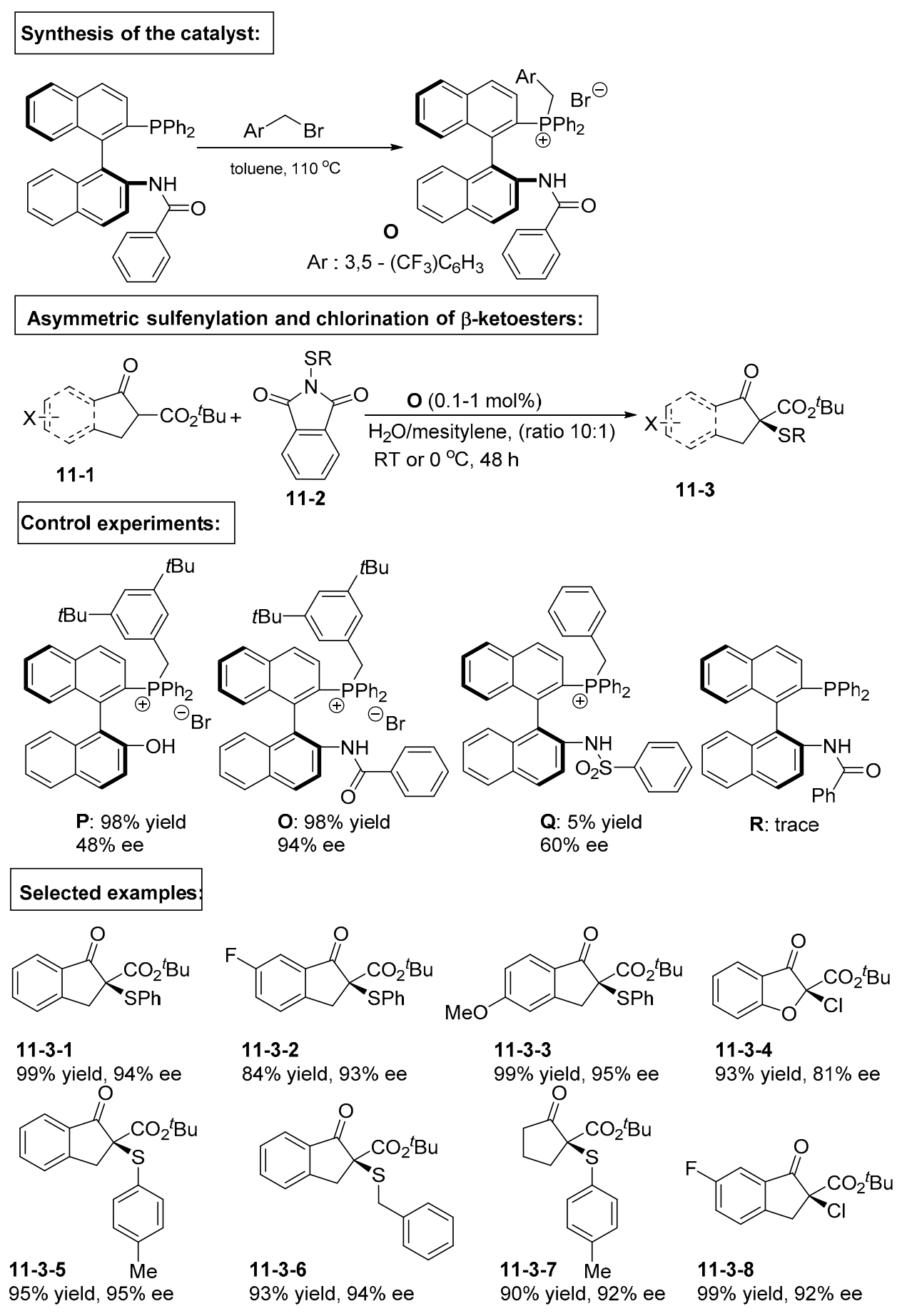

Scheme 11. Chiral quaternary phosphonium salts with amine group.

Maruoka's group also successfully developed a new family of bifunctional phosphonium salts with a urea group (Scheme 12) [28]. The hydrogen bonding interactions displayed remarkable 
influences in the control of the stereoselectivities of the $S_{N} A r$ reaction, and the $3,3^{\prime}$-diaryloxindoles can be effectively synthesized with high yields and excellent enantioselectivities. Notably, the chiral products were easily converted into other functional molecules under mild conditions via two steps without the loss of the enantioslectivities.

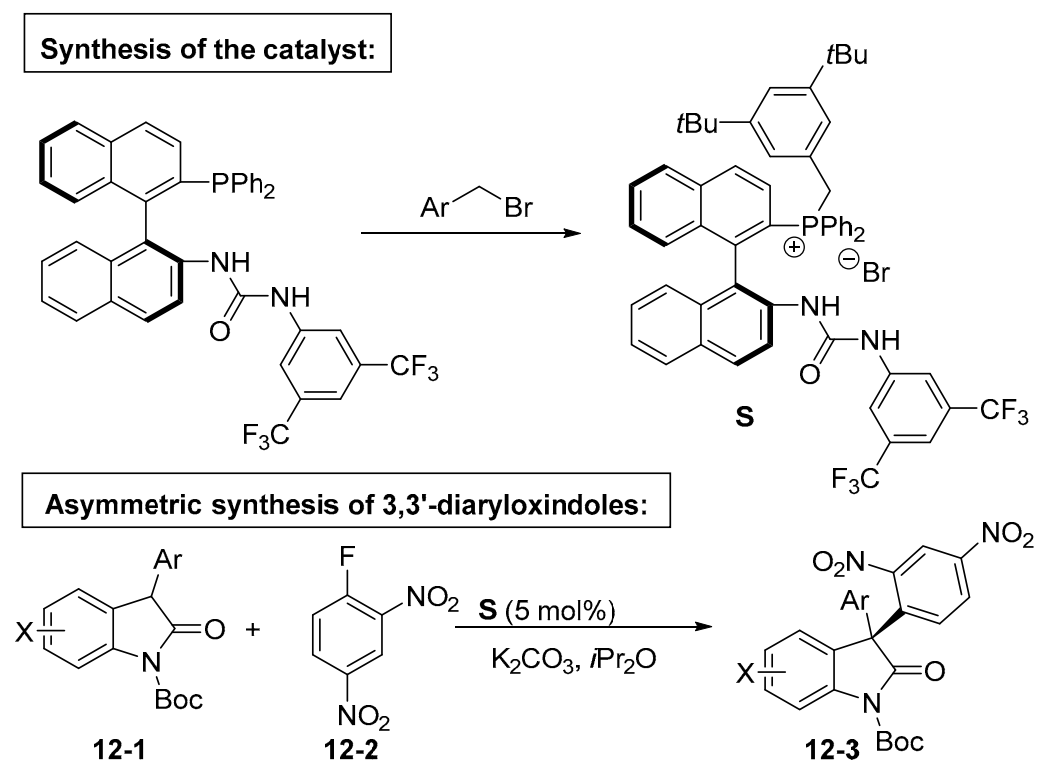

Selected examples:

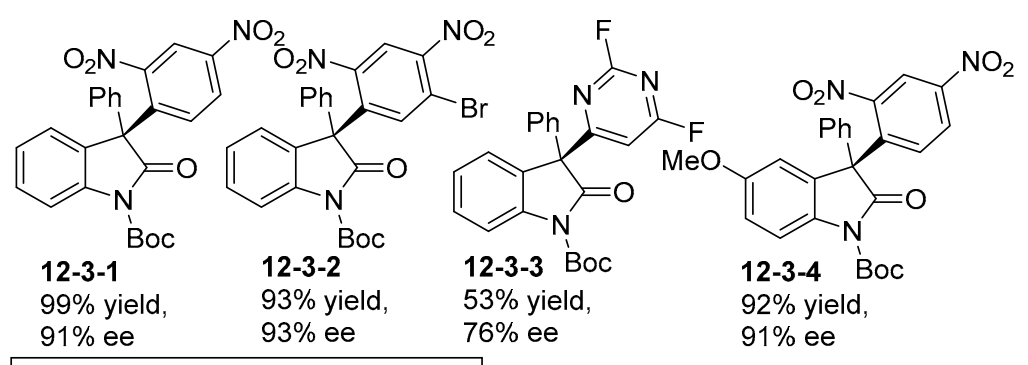

Representative transformations:

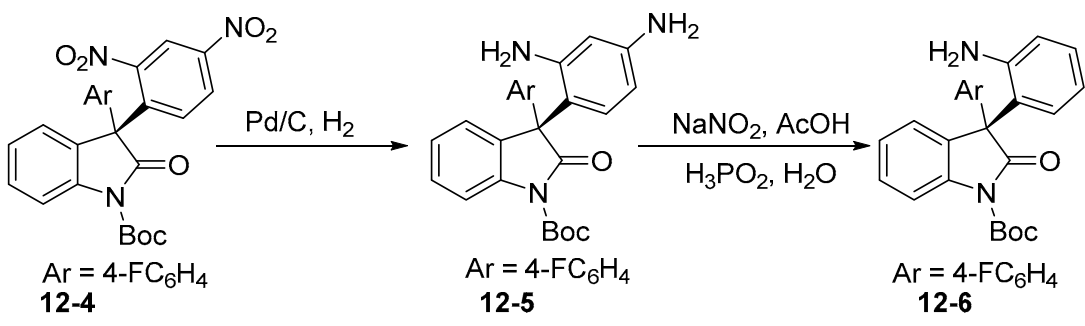

Scheme 12. Chiral quaternary phosphonium salts with urea.

Unlike quaternary ammonium and phosphonium salts, which have been well investigated as the phase-transfer catalysts, tertiary sulfonium salts were seldom explored as a family of catalyst due to its high reactivity and instability under basic conditions. Shirakawa' group firstly introduced the novel class of chiral phase-transfer catalysts that are based on the binaphthyl skeletons into asymmetric Michael addition reactions with excellent enantioselectivities (Scheme 13) [29]. 
Synthesis of the catalyst:

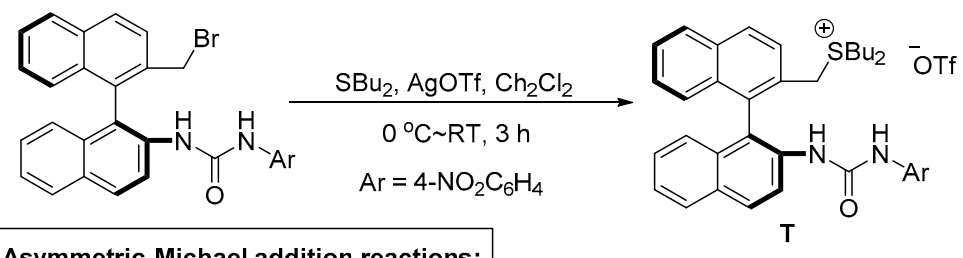

Asymmetric Michael addition reactions:

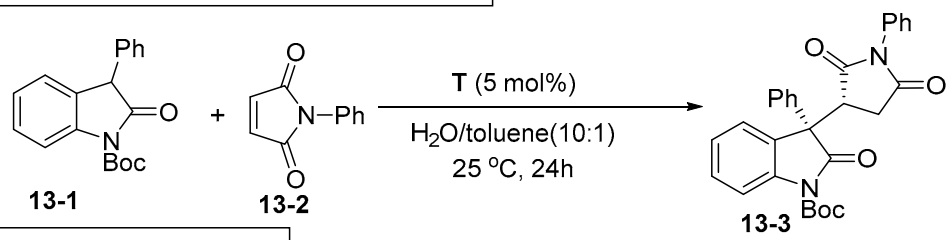

Control experiments:

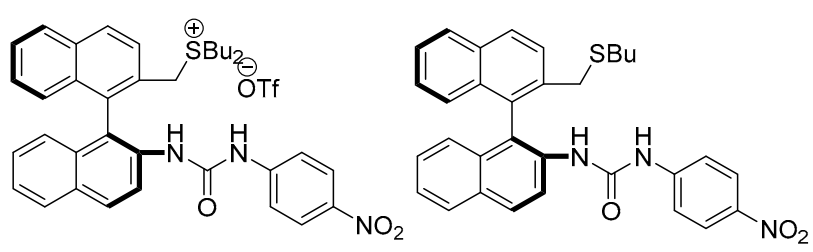

$\mathrm{T}$ : in $\mathrm{H}_{2} \mathrm{O} /$ toluene (10:1):

$64 \%$ yield, $91 \%$ ee, $92: 8 \mathrm{dr}$

$\mathrm{U}$ : in $\mathrm{H}_{2} \mathrm{O} /$ toluene (10:1):

in toluene (without $\mathrm{H}_{2} \mathrm{O}$ )

trace

trace<smiles>CC(C)(C)OC(=O)c1ccccc1C1([C@H]2CC(=O)N(c3ccccc3)C2=O)C(=O)N(c2ccccc2)c2ccccc21</smiles>

13-4

$64 \%$ yield, $91 \%$ ee

$92: 8 \mathrm{dr}$<smiles>CN1C(=O)C[C@H]([C@]2(c3ccccc3)C(=O)Nc3ccccc32)C1=O</smiles>

13-5

$17 \%$ yield, $86 \%$ ee $89: 11 \mathrm{dr}$<smiles>Cc1ccc2c(c1)[C@](c1ccccc1)([C@H]1CC(=O)N(c3ccccc3)C1=O)C(=O)N2</smiles>

13-6

$46 \%$ yield, $83 \%$ ee $87: 13 \mathrm{dr}$<smiles>COc1ccc(N2C(=O)C[C@H]([C@]3(c4ccccc4)C(=O)Nc4ccccc43)C2=O)cc1</smiles>

Boc

13-9

$59 \%$ yield, $83 \%$ ee 90:10 dr<smiles>O=C1C[C@H](Cc2ccc(F)cc2)C(=O)N1c1ccccc1</smiles><smiles>CCC1(C)C(=O)Nc2ccccc21</smiles>

$$
\text { 13-8 }
$$

$45 \%$ yield, $83 \%$ ee $85: 15 \mathrm{dr}$

The possible transition state:

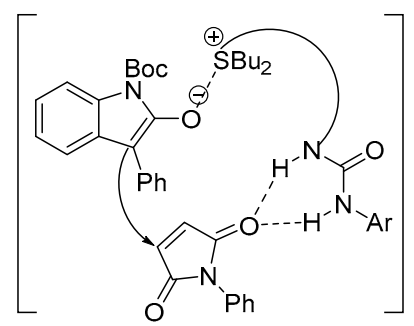

TM - 5

Scheme 13. Chiral tertiary sulfonium salts for asymmetric Michael addition reactions. 
As the reaction cannot take place in a homogeneous toluene system, the $\mathrm{H}_{2} \mathrm{O}$ /toluene biphasic solvent mixture plays a vital role in improving the yields and enantioselectivities. Moreover, the catalyst without the tertiary sulfonium salts center was ineffective in promoting the addition reaction. Through the exploration of the substrate scope, electron-withdrawing groups on the benzene ring of the oxindoles were beneficial for improving the yields of the products, while the electron-donating groups have a detrimental effect on the high yields. Meanwhile, the substrate with an alkyl group on the 3-site of the oxindoles cannot react with the maleimide. All suggested that the high reactivity of the substrates was important for the reaction using this family of chiral tertiary sulfonium salts under the base-free conditions, which may limit its applications. However, we believe that more and more tertiary sulfonium salts with new functional groups for novel asymmetric organic reactions will be reported in the future, and new applications that are based these catalysts will be discovered.

\section{Bifunctional Phase-Transfer catalysts derived from Amino Acid}

Amino acids as a family of privileged scaffolds due to their facile tuning of the catalytic efficiency via structural modifications have been widely applied in designing new catalysts [30-32]. Organic chemists also reported novel chiral phase-transfer catalysts that are based on the chiral backbones of the amino acids.

Ooi and co-workers reported a new family of chiral 1,2,3-triazoliums that are based on the amino acids via 10 steps (Scheme 14) [33]. The fine tuning properties of the catalysts make them suitable for many asymmetric reactions. Firstly, the asymmetric alkylation of oxindoles catalyzed this family of quaternary ammonium salts was investigated by their group. Fine tuning the structural groups of the 1,2,3-triazoliums can screen out the optimal catalyst for high yields and excellent ees. Importantly, the amide, as well as triazolium salt with proton donating groups, were essential in generating the corresponding products with the best results, as shown in Scheme 15. The wide scope of the asymmetric reactions illustrated the advantages of the bifunctional ammonium salts.

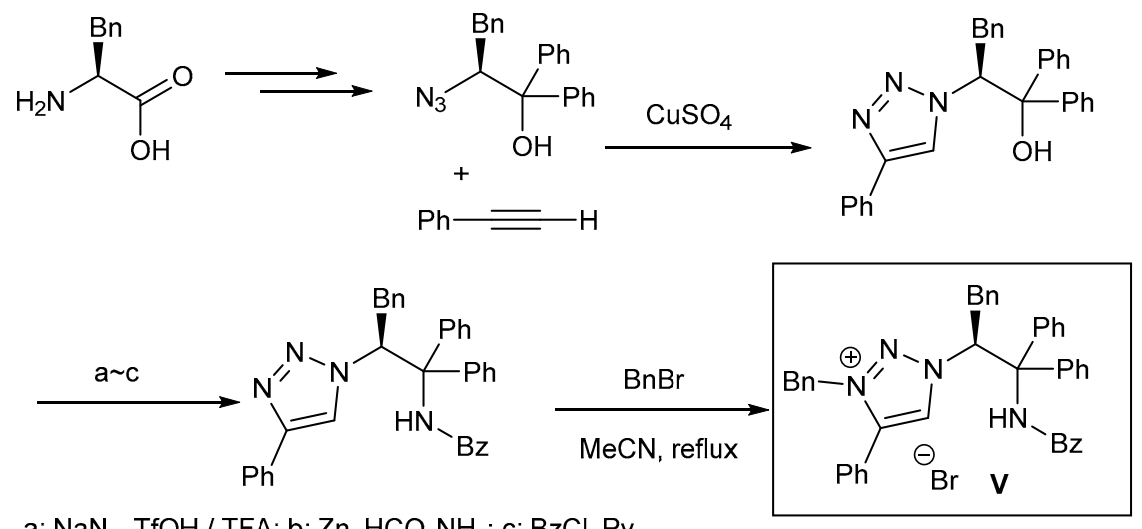

a: $\mathrm{NaN}_{3}, \mathrm{TfOH} / \mathrm{TFA}$; b: $\mathrm{Zn}, \mathrm{HCO}_{2} \mathrm{NH}_{4} ; \mathrm{c}: \mathrm{BzCl}, \mathrm{Py}$

Scheme 14. Bifunctional 1,2,3-triazolium salts. 


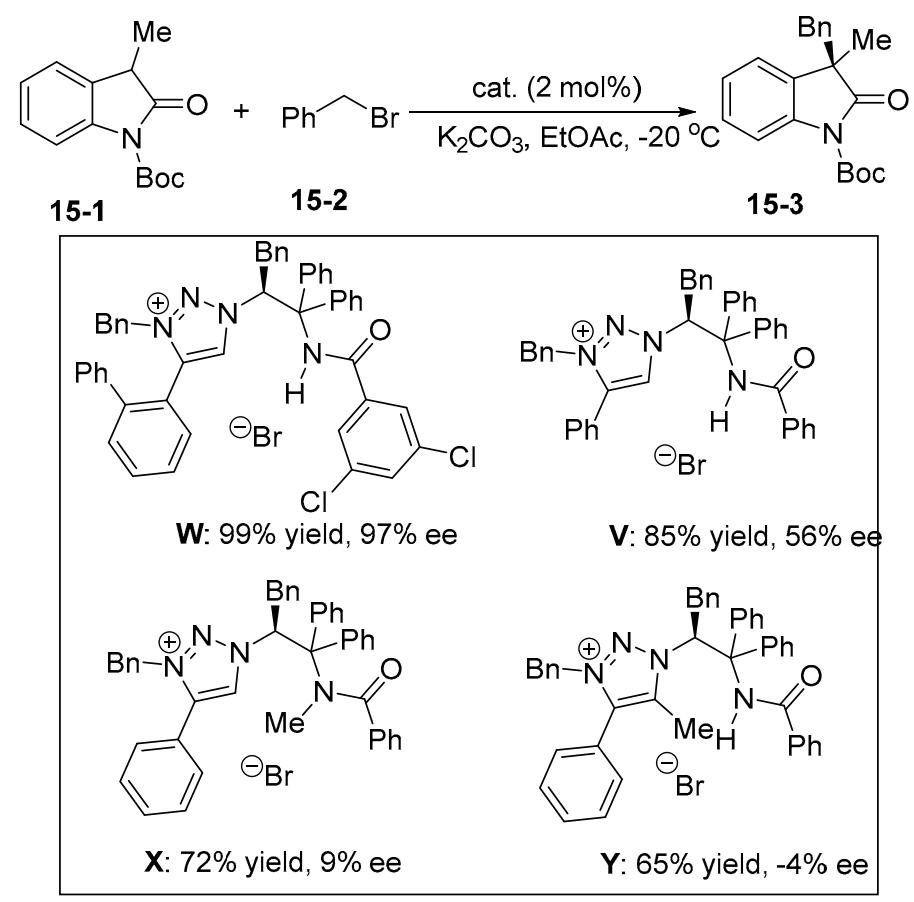

Scheme 15. Asymmetric alkylation of oxindoles catalyzed by 1,2,3-triazolium salts.

Halide ions as the nucleophiles are difficult for reacting with other electrophiles, as their ongoing project, Ooi reported asymmetric chloride and bromide ring openings of meso aziridines while using hypervalent silicates $\left(\mathrm{Me}_{3} \mathrm{SiCl}\right.$ ) (Scheme 16) [34]. After fine tuning the structure of the 1,2,3-triazolium salt, the addition reactions proceeded smoothly via the chloride ion transfer under the optimized conditions with excellent enantioselectivities and high yields. Importantly, 1 equiv. of $\mathrm{Me}_{3} \mathrm{SiOH}$ explained a significant role for high yield via proton transfer. Either acyclic aziridines or cyclic aziridines, including five-, six-, and seven-cycles, all tolerated furnishing the corresponding products with high yields and high ee values. Meanwhile, the kinetic resolution of racemic-terminal aziridines catalyzed the bifunctional 1,2,3-triazolium salt were successfully realized with high selectivities. Notably, this method exhibited high efficiencies for the kinetic resolution of 2,2-disubstituted aziridines, which were not readily accessible by conventional methodologies.

The enantioselective construction of the adjacently tetrasubstituted chiral carbon always stands out as a challenging project due to the bulky steric influences. Ooi reported an asymmetric ring-opening alkylation of racemic 2,2-disubstituted aziridines with 3-substituted oxindoles by the bifunctional 1,2,3-triazolium salt (Scheme 17) [35]. Fine tuning the groups of aziridines was not detrimental for excellent ee values and high yields, and the chiral pyrrolidinoindoline derivative can be easily synthesized via operationally simple transformations from the corresponding product. The kinetic experiments that were performed by the authors revealed a pseudo-first-order dependence on the ammonium salt and zero-order dependence on the aziridine and oxindole. The results provided new insights in the ongoing investigations on asymmetric phase-transfer catalysis. 

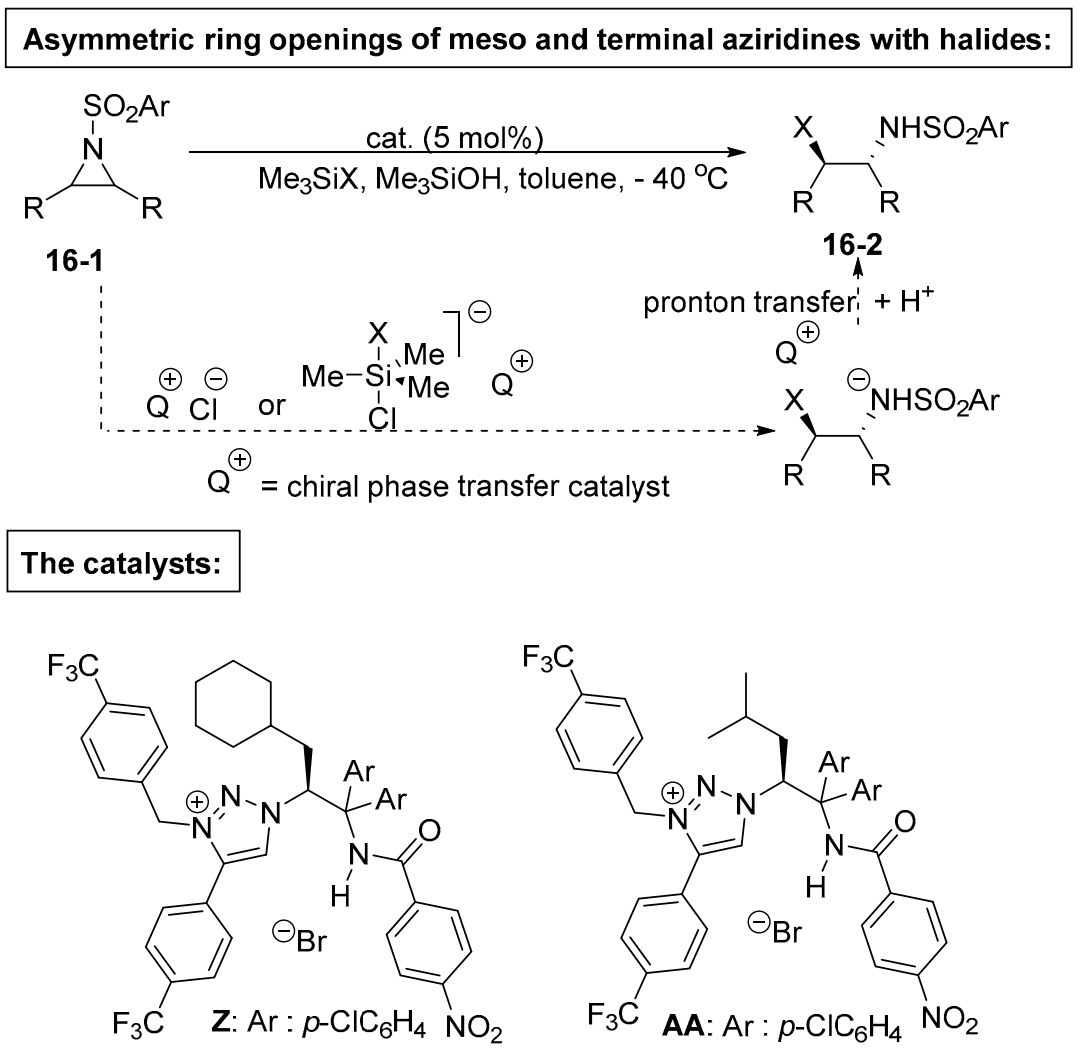

\section{Selected examples:}

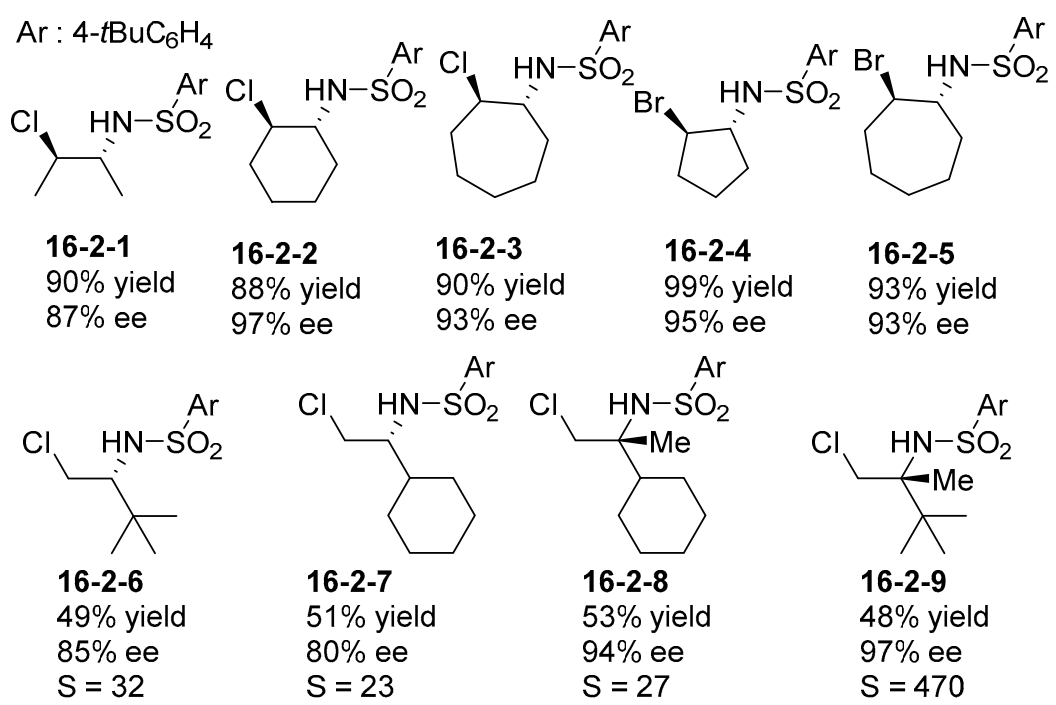

Scheme 16. Asymmetric ring openings of meso-aziridines.

The applications of $\alpha$-sulfonyl carbanions as the nucleophiles in constructing $\alpha$-chiral sulfonyl compounds represent an important strategy in organic synthesis. Ooi and co-workers applied their developed 1,2,3-triazolium salt into the asymmetric Mannich-type reactions while using $\alpha$-cyano, $\alpha$-sulfonyl carbanions under basic conditions (Scheme 18) [36]. Various substituted imines including aromatic, heteroaromatic, and aliphatic aldehyde-derived imines appeared to be well tolerated with high yields and high ees, irrespective of relatively low diastereoselectivities.

Chiral $\alpha$-aminocarbonyls, as important scaffolds that are present in bioactive molecules and biologically natural products, so the development of efficient methods for the stereoselective preparation of these compounds always stand out as an important field [30]. Among the great methods 
in this area, the direct $\alpha$-amination of carbonyl compounds is one of the optimal approaches. Ooi and co-workers reported a direct asymmetric $\alpha$-amination reaction of carbonyl compounds, yielding numerous chiral $\alpha$-aminocarbonyls with high ee values (Scheme 19) [37]. The in-situ generated $O$-imino hydroxylamines via the addition of hydroxylamines to trichloroacetonitrile enables the direct transfer of amine moieties to the oxindoles catalyzed by the bifunctional 1,2,3-triazolium salts. Through this protocol, the chiral 3-aminooxindoles with various substituents on nitrogen were well tolerated, and other carbonyl compounds, including $\alpha$-cyanoesters and $\beta$-ketoesters, were also carried out to give the corresponding products with high ee values.

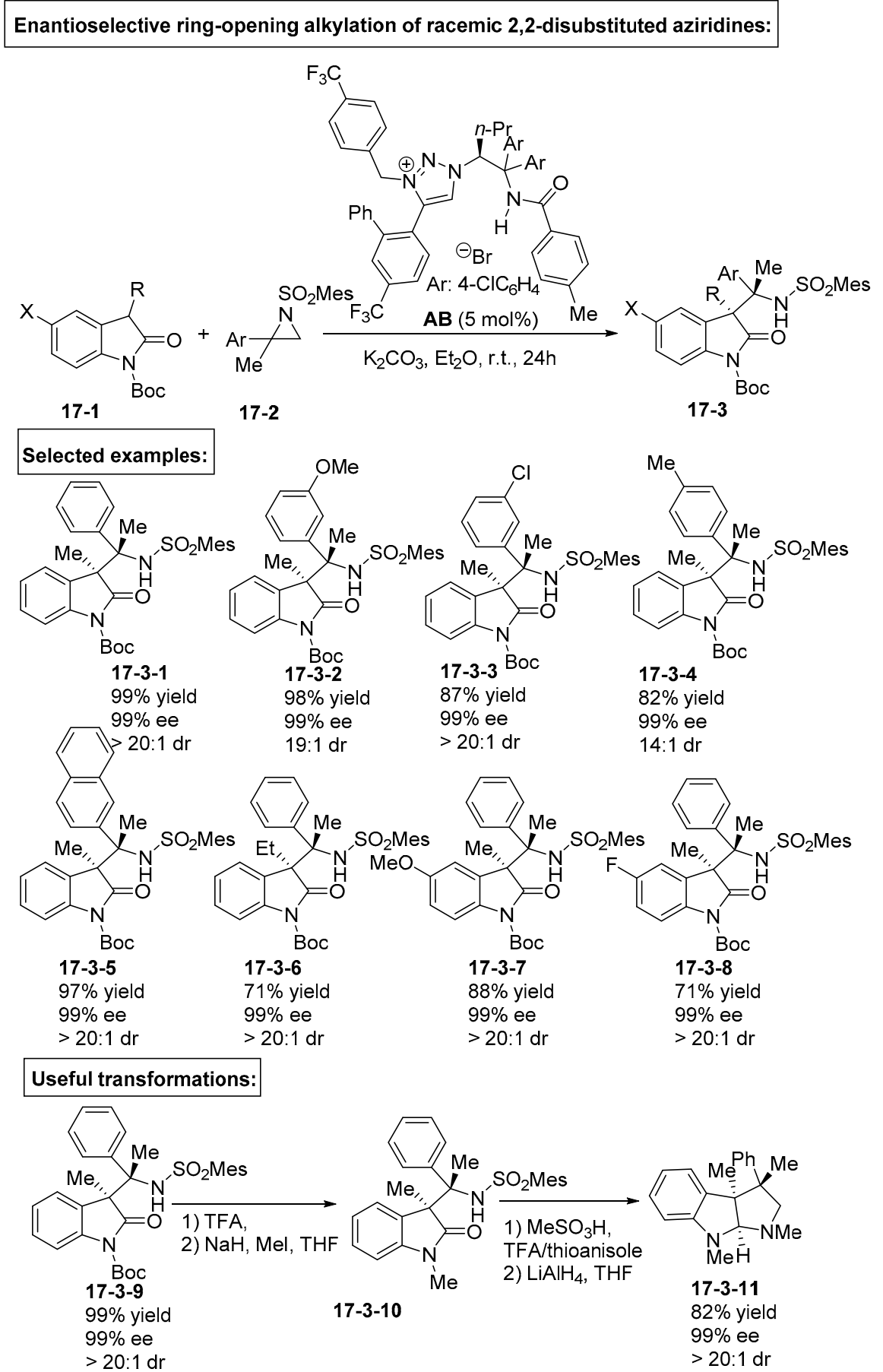

Scheme 17. Bifunctional 1,2,3-triazolium salt for asymmetric alkylation of 2,2-disubstituted aziridines. 


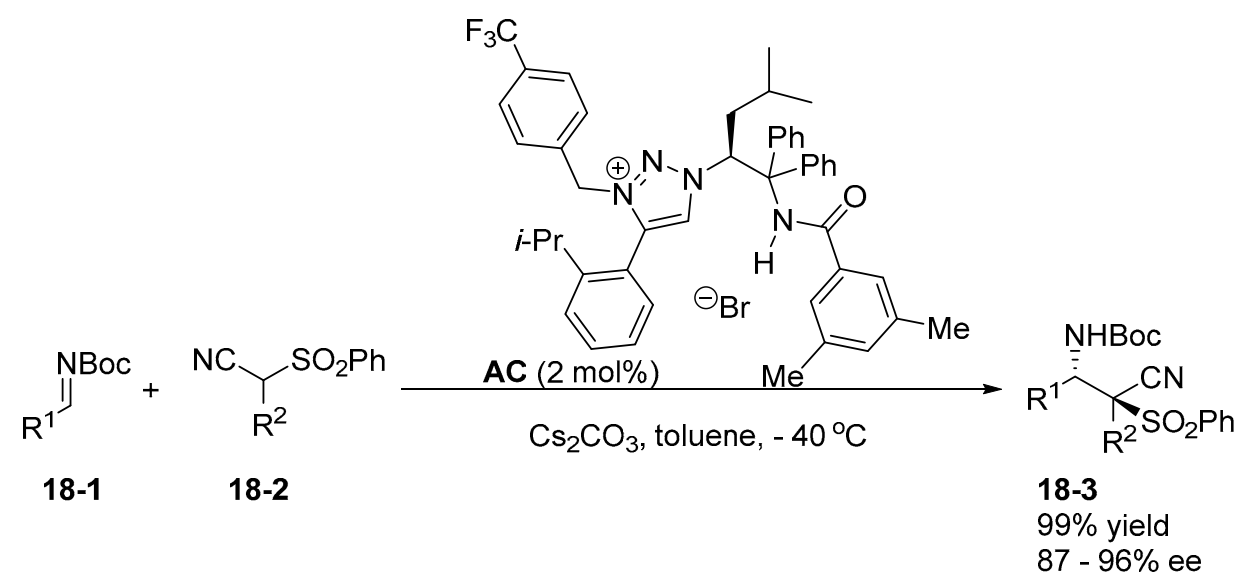

Scheme 18. Asymmetric Mannich reactions catalyzed by 1,2,3-triazolium salts.

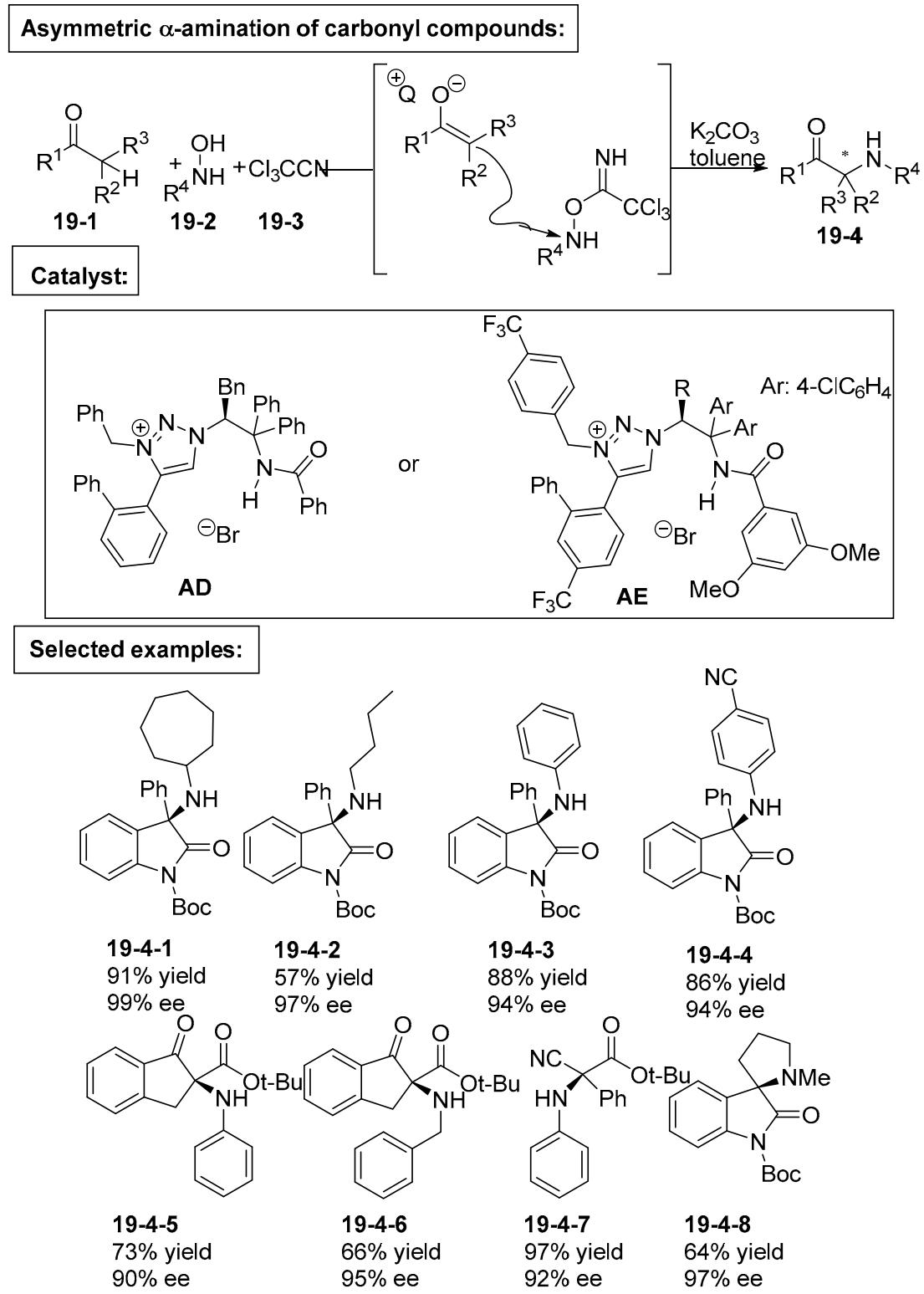

Scheme 19. Asymmetric $\alpha$-amination of carbonyl compounds. 
Replacing the hydroxylamines with $\mathrm{H}_{2} \mathrm{O}_{2}$, the asymmetric $\alpha$-hydroxylation reactions of 3-substituted oxindoles were reported by Ooi and co-workers (Scheme 20) [38]. The control experiments demonstrated the importance of the in-situ generated peroxy trichloroacetimidic acid (with $\mathrm{Cl}_{3} \mathrm{CN}, 65 \%$ ee, $65 \%$ yield; whithout $\mathrm{Cl}_{3} \mathrm{CN}$, no reaction). The quaternary ammonium salt was suitable for a wide scope, which provided a new method for preparing chiral tertiary $\alpha$-hydroxyl compounds.

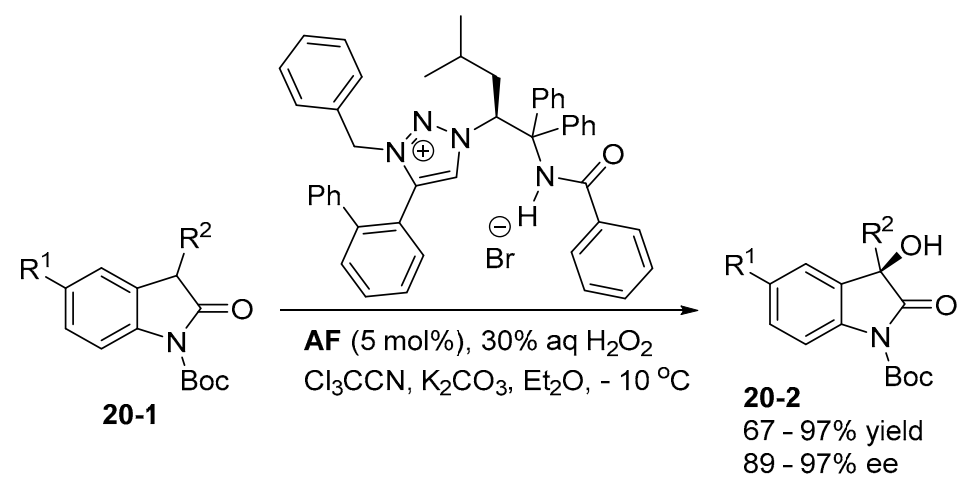

Scheme 20. Asymmetric $\alpha$-hydroxylation of 3-substituted oxindoles.

In 2013, Zhao and co-workers realized the bifunctional ammonium salts with (thio)-urea motifs that are based on the acyclic amino acid. As shown in Scheme 21, if the nitrogen atom was protected with a methyl group, only $5 \%$ ee was achieved. Meanwhile, the precursor of the catalyst, without the ammonium center, was detrimental for excellent enantioselectivities. Due to the multi easy-fine-tuning-sites of the bifunctional phase-transfer catalysts, they have been successfully employed in the asymmetric Mannich-type reactions and high ees and yields were obtained [39,40].

The heterocyclic skeletons exist in numerous natural and unnatural compounds, often conferring bioactivity and pharmaceutical properties. Zhao and co-workers realized a highly enantioselective 1,3-dipolar cycloaddition of imino esters with methyleneindolinones utilizing thiourea-quaternary ammonium salts, and a range of chiral spiro[pyrrolidin-3,3'-oxindoles] were facilely yielded with excellent enantioselectivities [41]. Control experiments explained the bifunctional property of the ammonium salts, as shown in Scheme 22. No matter removing the hydrogen bonding interaction or the columbic force, all gave almost racemic products with low yield. Furthermore, Zhao and co-workers also recently realized enantioselective cycloaddition reactions between benzofuranones and imino esters (Scheme 23) [42].

Chiral dialkylated $\alpha$-hydroxy carboxylic acids bearing a tertiary hydroxyl stereogenic center are important intermediates in synthesizing biological molecules [43]. For efficiently accessing these compounds under phase-transfer catalytic conditions, the asymmetric alkylation of $5 \mathrm{H}$-oxazol-4-ones with benzyl bromides and allylic bromides was reported by Jiang and co-workers while utilizing urea-ammonium salts (Scheme 24) [44]. During the exploration of the catalysts, thiourea-ammonium salts, which were firstly developed by Zhao and co-workers, could not improve the ees (with only $5 \%$ ee). However, urea-ammonium salts were more suitable for asymmetric alkylation. In addition, the transformations from alkylation products can be easily performed under mild conditions furnishing dialkylated $\alpha$-hydroxy carboxylic acids. 


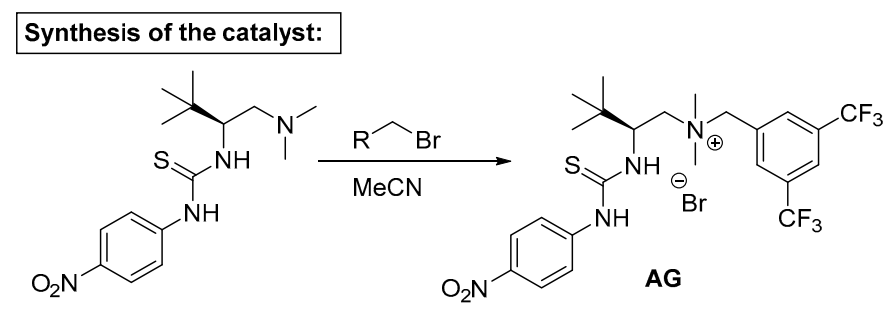

$$
\text { Asymmetric addition reactions of imines: }
$$

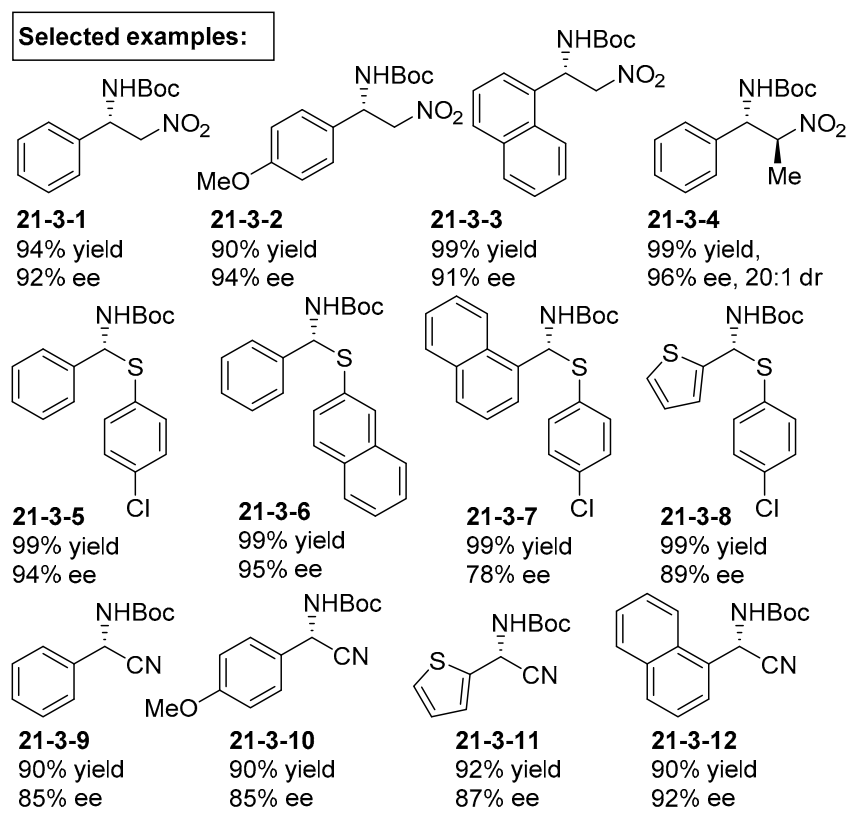

Control experiments:

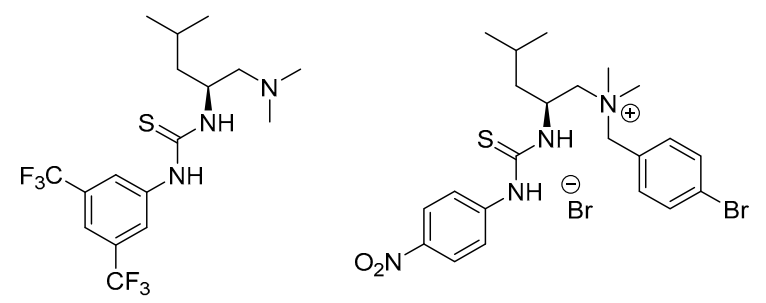

AH: $95 \%$ yield, $3 \%$ ee for $\mathbf{2 1 - 3 - 1}$ Al: $97 \%$ yield, $5 \%$ ee for $\mathbf{2 1 - 3 - 1}$

The possible transition state:

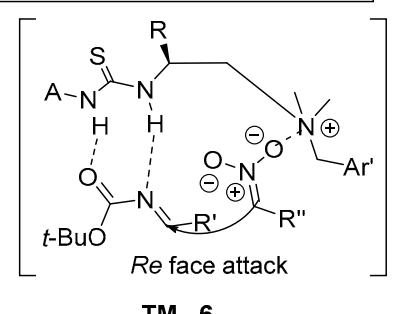

TM - 6

Scheme 21. Novel bifunctional quaternary ammonium salts for asymmetric addition reactions of imines. 
<smiles>[R]C=C1C(=O)N([R9])c2ccc([R1])cc21</smiles>

22-1

22-2

22-3

up to $99 \%$ yield

up to $99 \%$ ee

$>19: 1 \mathrm{dr}$

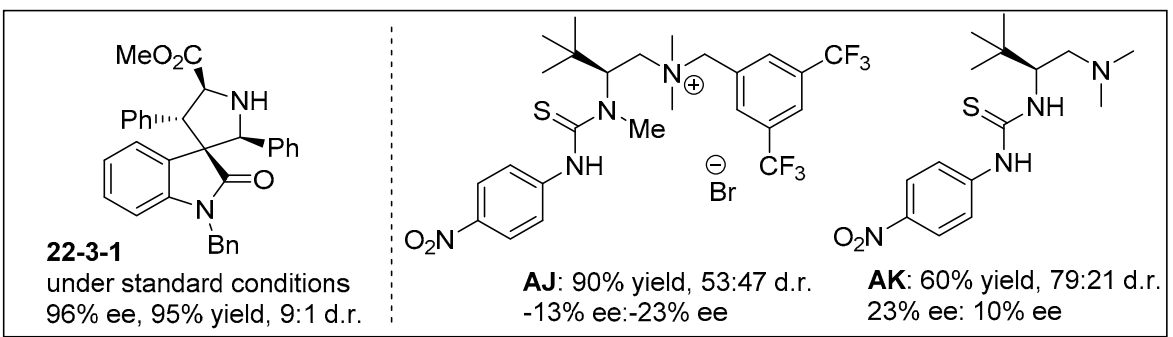

Scheme 22. Asymmetric dipolar cyclizations catalyzed by thiourea-quaternary ammonium salts.

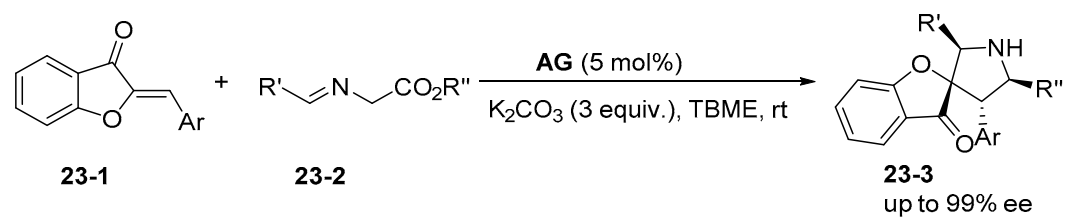

Scheme 23. Asymmetric [3+2] cyclization reactions.

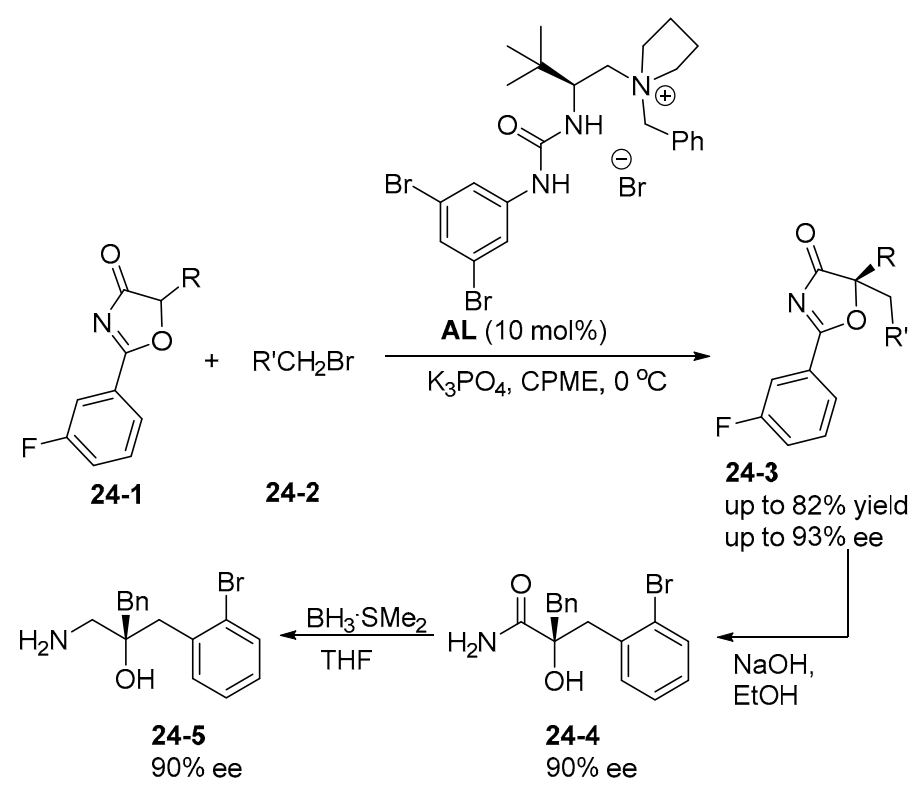

Scheme 24. Asymmetric alkylation of $5 H$-oxazol-4-ones.

Although the (thio)-urea group showed a vital role in designing novel catalysts, the expensive iso(thio)cyanate limited its wide applications in industrialization. The carboxylic acids with variously functional groups are commercially available in low-cost, which generally reacted with the primary amines furnishing the amide as a proton donating group. Currently, some outstanding catalysts that are based on these proton donating groups have been created for the asymmetric organic reactions. Zhao and co-workers independently synthesized a new class of bifunctional ammonium salts with the amides (Scheme 25) [45]. The asymmetric Michael addition reactions proceeded well to affording the various 3,3-disubstituted oxindoles with stereogenic centers with high yields and high ee values. 


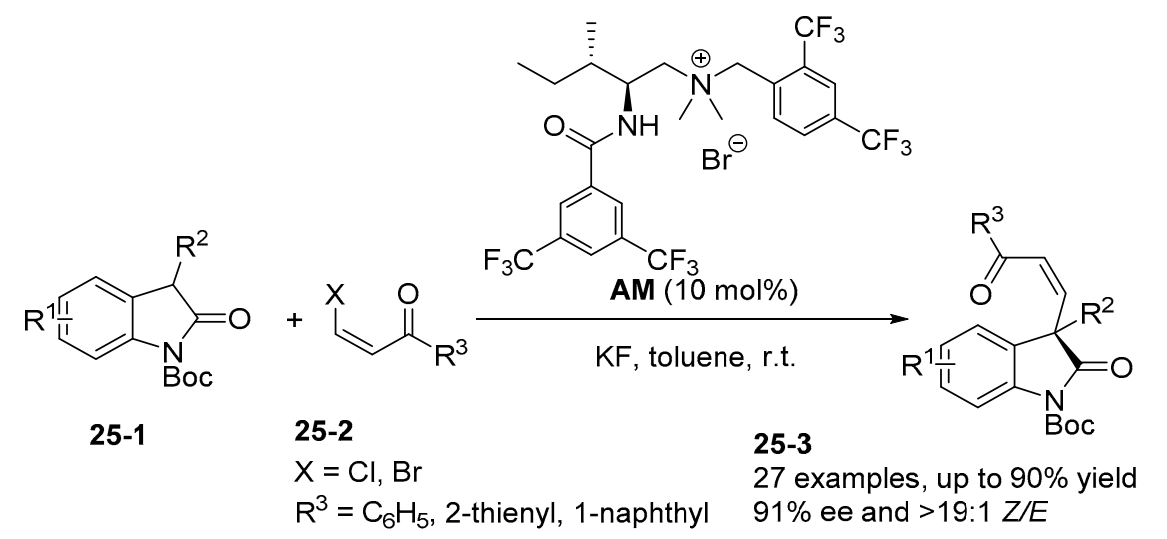

Scheme 25. Asymmetric Michael addition reactions catalyzed by chiral ammonium salts.

When compared to the widely exploration of the chiral ammonium salts, the development of the phosphonium salts as the chiral phase-transfer catalysts has evolved slowly in the past decades. To some extent, it might be attributed to the ready elimination of phosphoniums under the basic conditions. Although impressive progress have been made by the groups of Maruoka, Lectka, Ma, and Ooi, Zhao and co-workers developed a new class of chiral bifunctional quaternary phosphonium salts derived from acyclic amino acids (Scheme 26) [46]. The asymmetric aza-Henry reactions were efficiently catalyzed by these catalysts, with excellent enantioselectivities and high yields. The dual hydrogen-bonding sites and the phosphonium center played vital roles in accelerating the reactions and improving the enantioselectivities, according to the results of the control experiments.

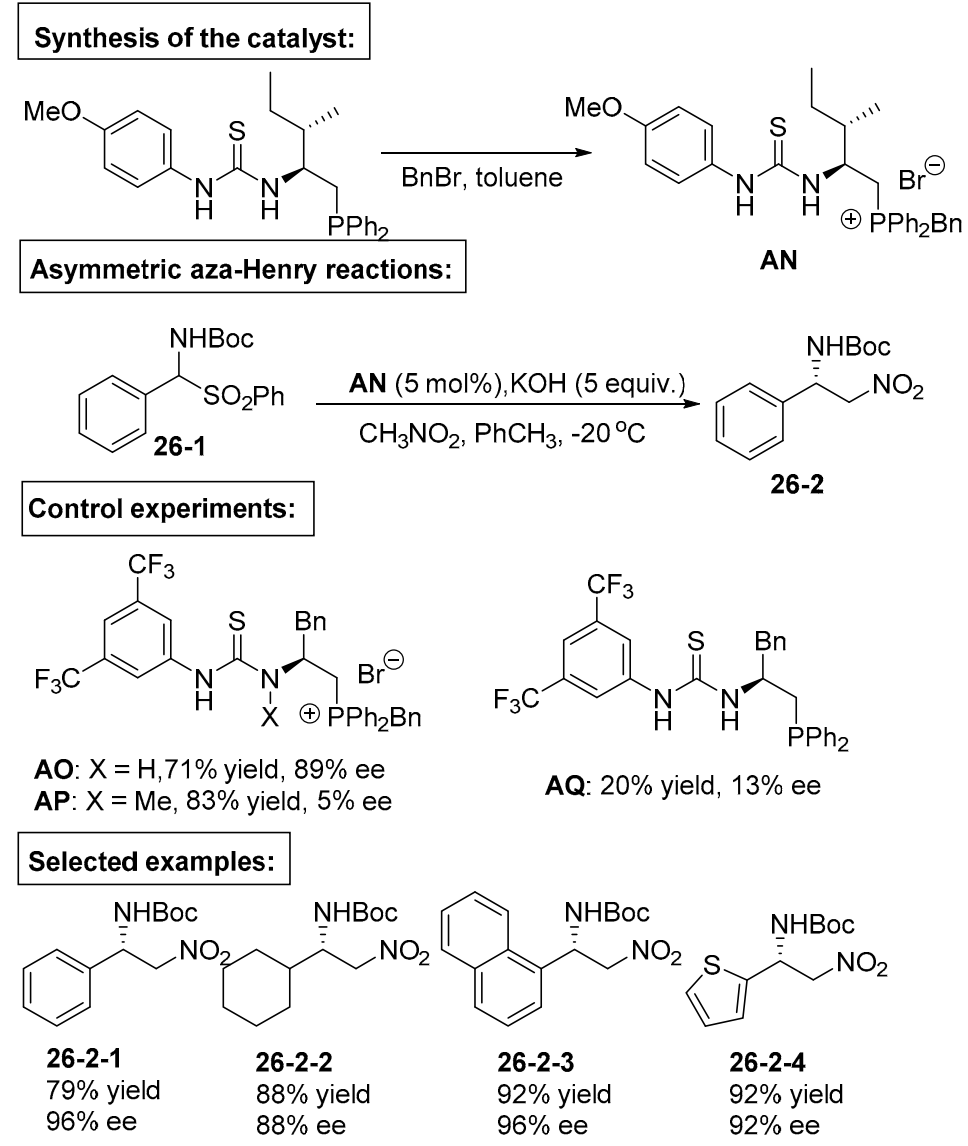

Scheme 26. Bifunctional quaternary phosphonium salts derived from amino acids. 
The asymmetric Strecker reaction has been emerging as important method for constructing natural and unnatural amino acids since its discovery. However, the ketimines in the Strecker reaction are less investigated when compared to aldimines, which are useful substrates for synthesizing amino acids that bear chiral quaternary stereocenters. Zhao and Tang reported an asymmetric Strecker reaction that involved ketimines derived from isatins utilizing the thiourea-phosphonium salts (Scheme 27) [47]. Through this method, synthetically useful 3-amino-3-cyanooxindoles with excellent enantioselectivities were efficiently prepared in a short time. According to the mechanistic experiments, including ${ }^{1} \mathrm{H}-\mathrm{NMR}$ and ${ }^{31} \mathrm{P}-\mathrm{NMR}$, the author speculated that the in-situ generated betain was the real catalyst for inducing the asymmetric addition reaction.
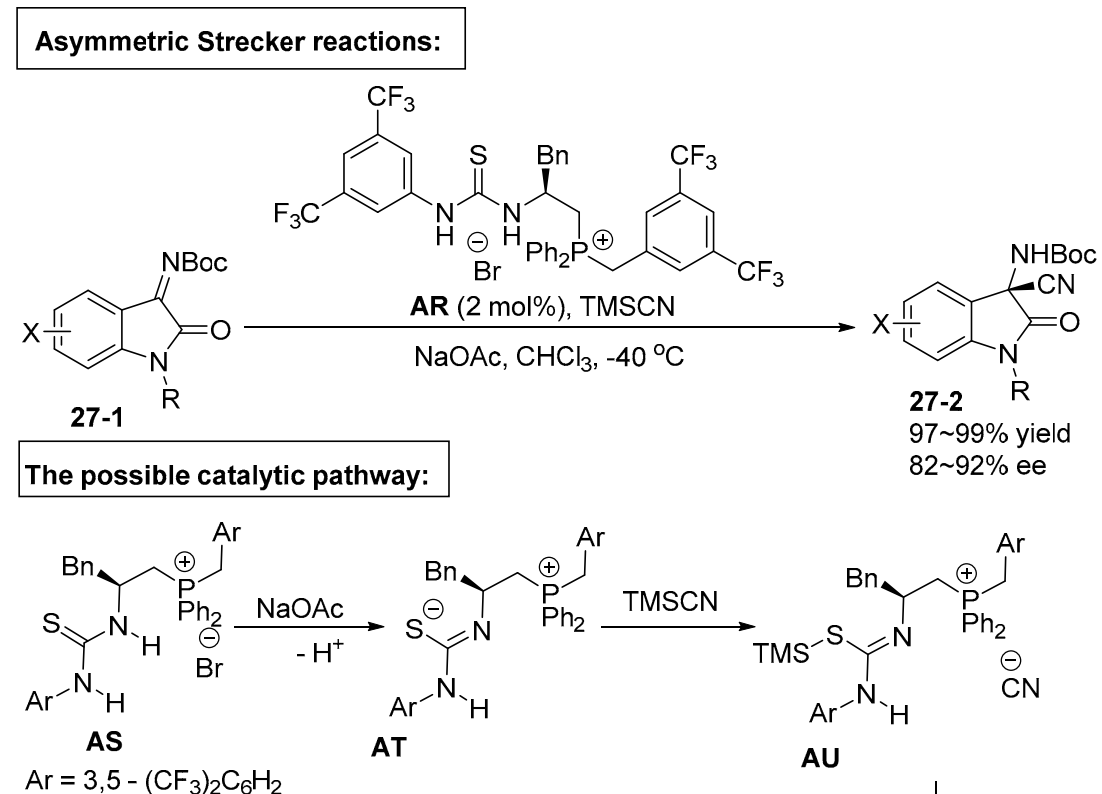

$\mathrm{Ar}=3,5-\left(\mathrm{CF}_{3}\right)_{2} \mathrm{C}_{6} \mathrm{H}_{2}$

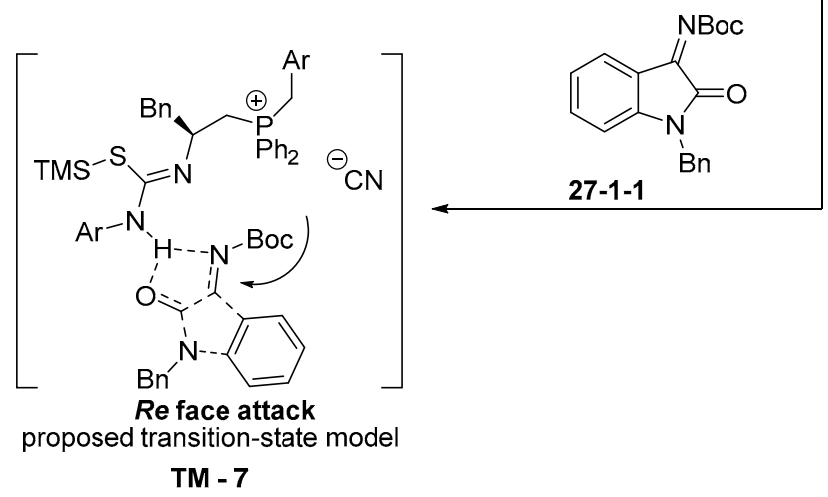

Scheme 27. Asymmetric Strecker reactions of ketimines.

$\mathrm{Wu}$ and co-workers also developed the bifunctional phosphonium salt with a single hydrogen bond that is derived from amino acid (Scheme 28) [48]. This family of chiral phase-transfer catalyst were generally prepared utilizing commercial-available tertiary-substituted phosphines. After screening the conditions of the Michael reaction between 3-monosubstituted oxindoles and activated olefins, the corresponding products have been furnished with excellent enantioselectivities and high yields that are catalyzed by the bifunctional phosphonium salt at $-70^{\circ} \mathrm{C}$. However, the substituent on the amide of the catalyst was limited to the $3,5-\mathrm{CF}_{3}$ benzoyl group, which would be detrimental in expanding the scope of the application of these chiral bifunctional phosphonium salts. 


\section{Synthesis of the catalyst:}

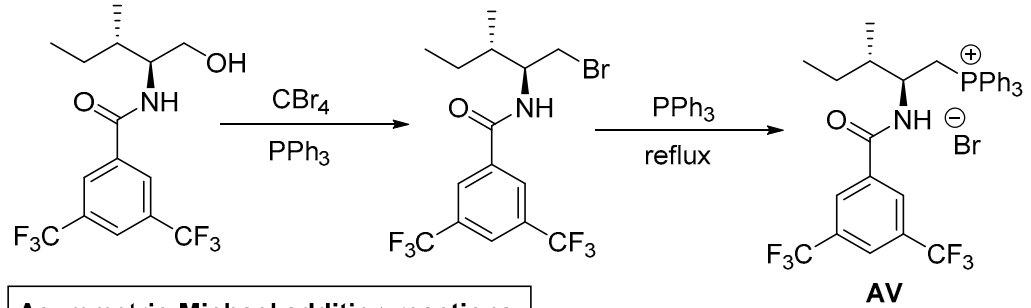

Asymmetric Michael addition reactions:

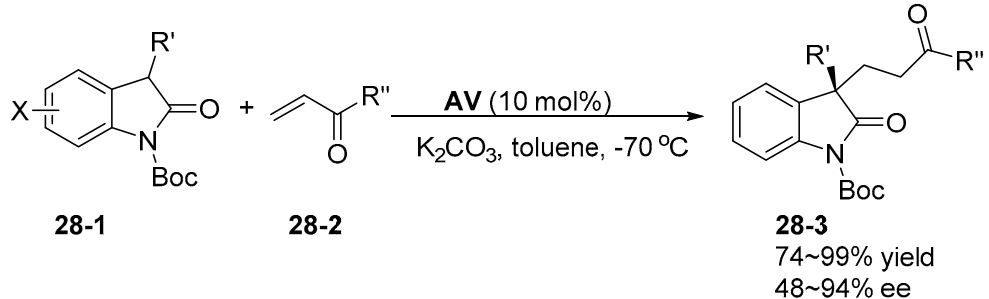

Scheme 28. Novel quaternary phosphonium salts for asymmetric Michael addition reactions.

The para-quinone methides are present in numerous natural products and it has been widely investigated as new electrophile for asymmetric 1,6-addition reactions. Fan and co-workers firstly reported an asymmetric 1,6-additions between para-quinone methides and diphenyl malonates while using ammonium salts derived from binaphthyl [49]. Based on the work, Wu applied the bifunctional phosphonium salts with amide groups into the similar asymmetric 1,6-addition reaction (Scheme 29) [50]. Various substituents on the phenyl ring of the para-quinone methides were well tolerated in providing the corresponding diarylmethines with high yields and ee values, which can be transformed into $(R)$-methyl 3-(4-hydroxyphenyl)-3-phenylpropanoate for the preparation of GPR40 agonists.

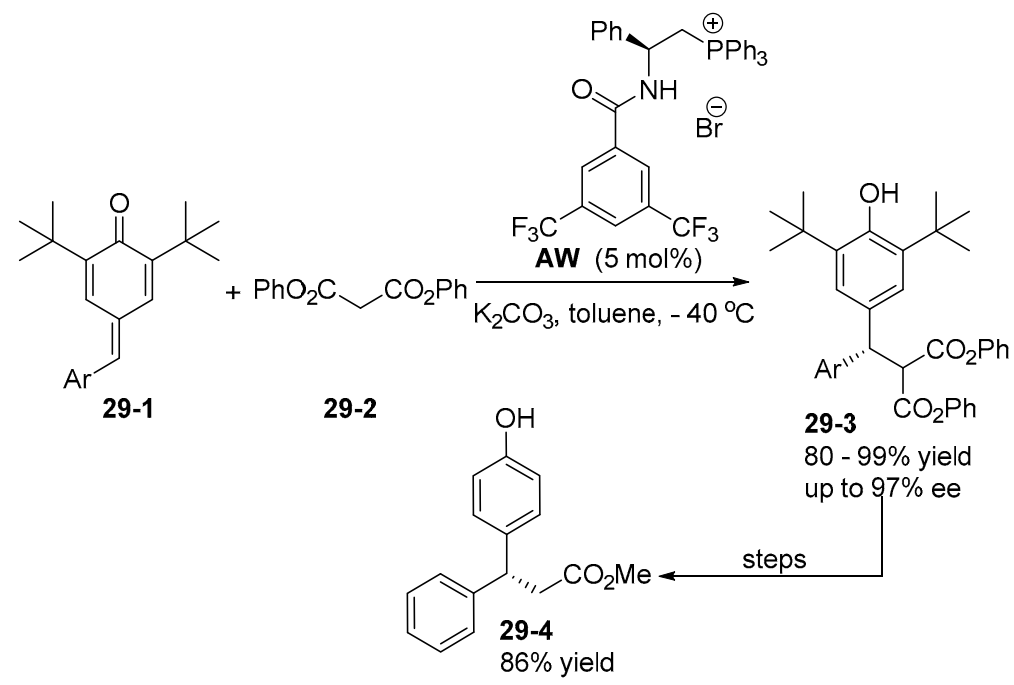

Scheme 29. Asymmetric 1,6-addition reactions catalyzed by bifunctional quaternary phosphonium salts.

Subsequently, $\mathrm{Wu}$ and co-workers, using their developed phosphonium salts, reported an asymmetric vinylogous Mannich-type reaction between the ketimines that were derived from isatins and $\alpha, \alpha$-dicyanoolefins (Scheme 30) [51]. A variety of substituents with electron-withdrawing groups and electro-donating groups on the phenyl ring of the substrates were well tolerated in high yields and ee values. Notably, the products can be easily scaled up and then transformed into other functionalized molecules. Lu and co-workers also reported asymmetric alkylation of glycine imine reactions that 
were promoted by this class of bifunctional phase-transfer catalysts, affording the substituted glycine imines with high yields and ees (Scheme 31) [52].

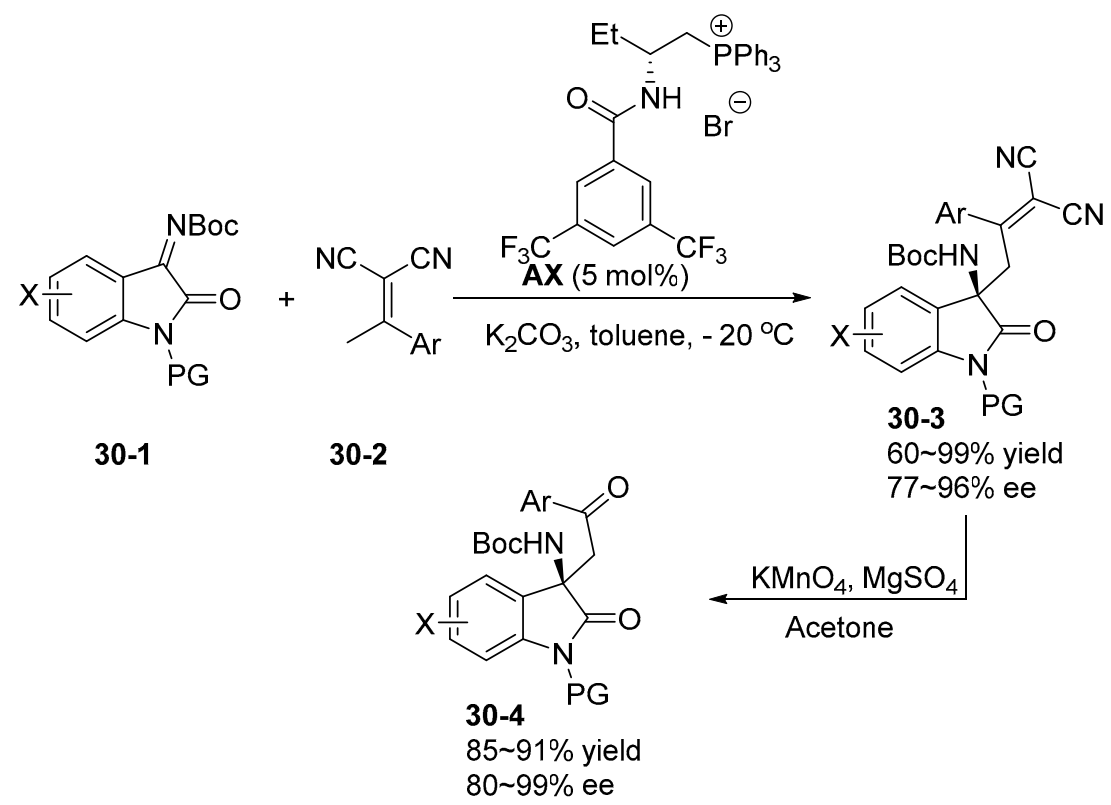

Scheme 30. Asymmetric vinylogous Mannich-type reaction catalyzed by quaternary phosphonium salts.

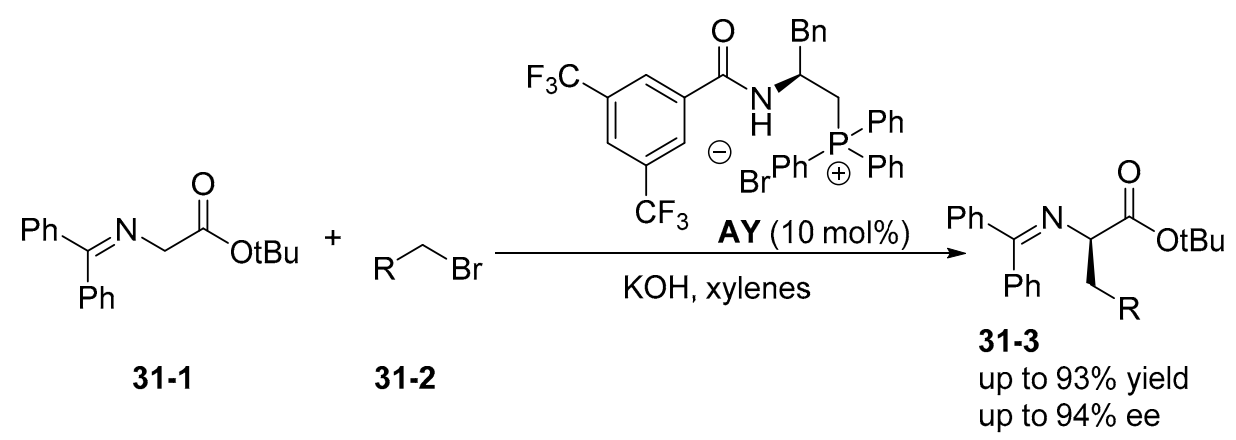

Scheme 31. Asymmetric alkylation of glycine imine.

The enantioselective desymmetrization of meso-aziridines with nucleophiles occupies a significant role in the preparation of various substituted chiral amines. Zhao and Shang developed a new approach for the desymmetrization of meso-aziridines while using aromatic thiols catalyzed by the chiral bifunctional phosphonium salts bearing a single hydrogen bond (Scheme 32) [53]. This family of the bifunctional phosphonium salts were prepared by the alkylation of the corresponding chiral phosphine. Although only moderate ee values were obtained after the careful exploration of the scope with different thiols, the easy-available-bifucntional phosphonium salts with amides might find new applications in the future. 


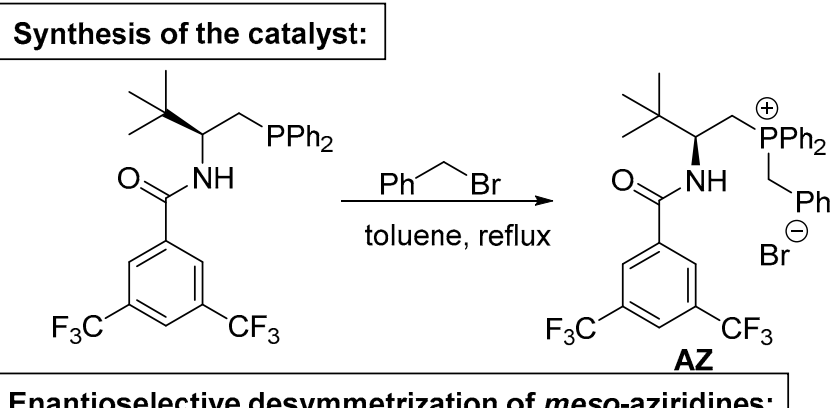

Enantioselective desymmetrization of meso-aziridines:
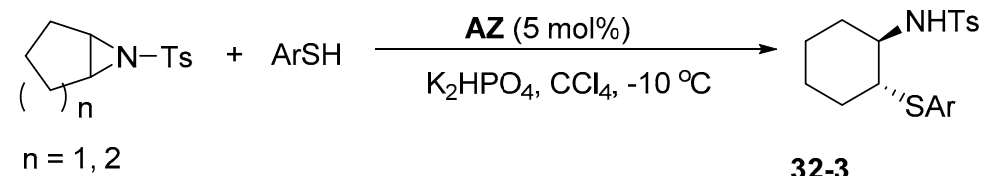

32-1

32-2

32-3

60 98\% yield $44 \sim 70 \%$ ee

Scheme 32. Enantioselective desymmetrization of meso-aziridines catalyzed by quaternary phosphonium salt with amide.

To introduce the nitrile group into chiral molecules, Zhao and Cao developed an asymmetric Mannich-type reaction while utilizing the activated cyanoacetates and various imines (Scheme 33) [54]. Bifunctional phosphonium salt, which affords the corresponding compounds with excellent enantioselectivities, albeit with low diastereoselectivities, efficiently catalyzes the reactions. Notably, the nitro group of the nucleophile was important for improving the ees, only the 2-nitrophenyl acetonitrile was suitable for the asymmetric Mannich-type reaction according to the control experiments, including 3-nitrophenyl acetonitrile and 4-nitrophenyl acetonitrile. Accordingly, the nitro group might direct the reaction to control the enantioselectivity in the transition state. Recently, Lu and co-workers also reported asymmetric Michael addition reactions utilizing glycine imines and activated alkenes in 2016 (Scheme 34) [55]. The corresponding products were generated in high yields and ee values in the presence of the bifunctional phosphonium salts.

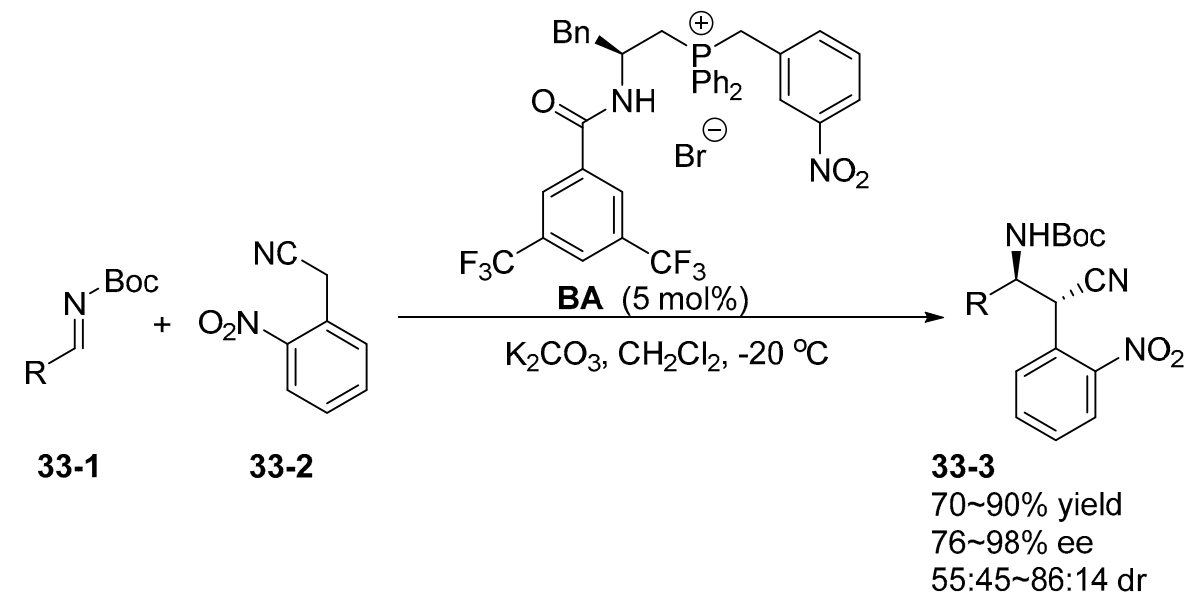

Scheme 33. Asymmetric Mannich-type reactions catalyzed by bifunctional quaternary phosphonium salts. 


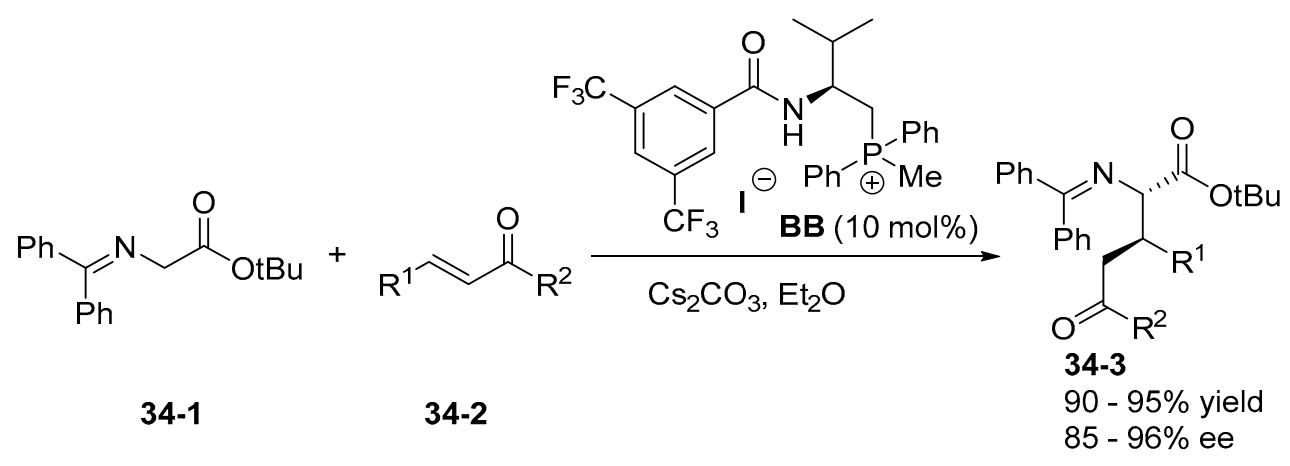

Scheme 34. Asymmetric Michael addition reactions catalyzed by chiral quaternary phosphonium salts.

Peptides exist in numerous biological molecules and natural products, which are also widely applied in designing novel catalysts due to their high structural modularity. Based on the strategy, Zhao and co-workers successfully developed a novel family of dipeptide-based multifunctional phosphonium salts as chiral phase-transfer catalysts [56]. Inspired by asymmetric cascade reactions as powerful approaches for preparing cyclic molecules, a large number of new strategies, such as organocatalysis and metal-catalysis, have been developed in order to directly construct these chiral molecules [57-59]. However, asymmetric phase-transfer catalysis as an important method for preparing chiral compounds has limited successes in this field. For broadening the scope of the phase-transfer catalysis, Zhao and co-workers realized a Michael addition $/ \mathrm{S}_{\mathrm{N}} 2$ sequence reaction that furnishes chiral five- and six-membered carbocycles and heterocycles with excellent enantioselectivities while using the dipeptide-based phosphonium salt under the basic conditions (Scheme 35). After the useful transformations of the product over a two-step procedure, chiral bicyclic lactam and chiral bicyclic lactone were prepared without the loss of enantioselectivity. Meanwhile, the direct Michael addition reactions between malonates and chalcone derivatives were reported (Scheme 36) [60], which possessed a wide scope of the substrates that utilized the chiral phase-transfer catalyst. Importantly, removing the hydrogen bonding interaction or the phosphonium salts were detrimental for the reactions, and almost racemic products were yielded at last. They all demonstrate the importance of the hydrogen bonding interaction and electrostatic force in the multifunctional phosphonium salts. In addition, asymmetric tandem Michael-Michael addition reactions involving 2-substituted malonates and a variety of chalcones were subsequently achieved (Scheme 37) [61]. The dipeptide-based multifunctional phosphonium salts exhibited excellent properties in these reactions in obtaining functionalized chiral cyclopentanes with high yields and high ees. Owing to the privileged motif of chiral spirocyclic oxindole scaffold, Zhao and co-workers successfully realized the tandem Michael-Michael addition reactions between $\gamma$-malonate-substituted $\alpha, \beta$-unsaturated esters and methyleneindolinone while using dipeptide-based quaternary phosphonium salts with the amide hydrogen [62]. The control experiments also illustrated the importance of the hydrogen bonding interactions and the electrostatic interactions (Scheme 38). 


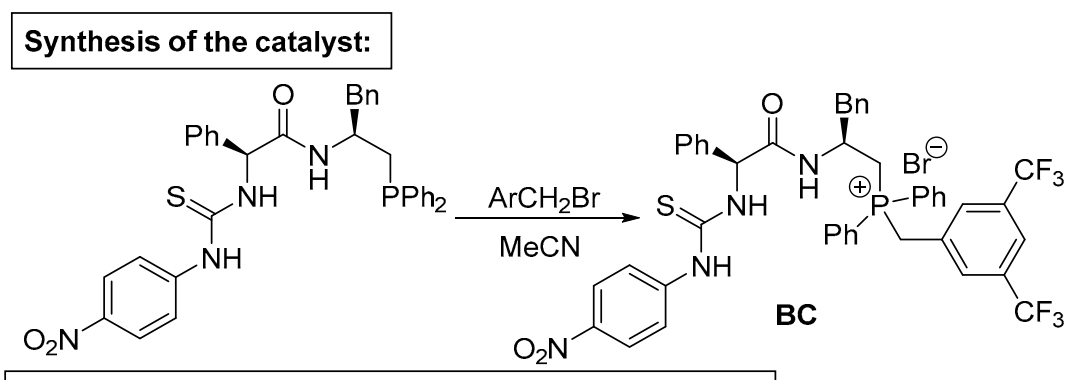

Asymmetric Michael addition/ $\mathrm{S}_{\mathrm{N}} 2$ sequence reactions:
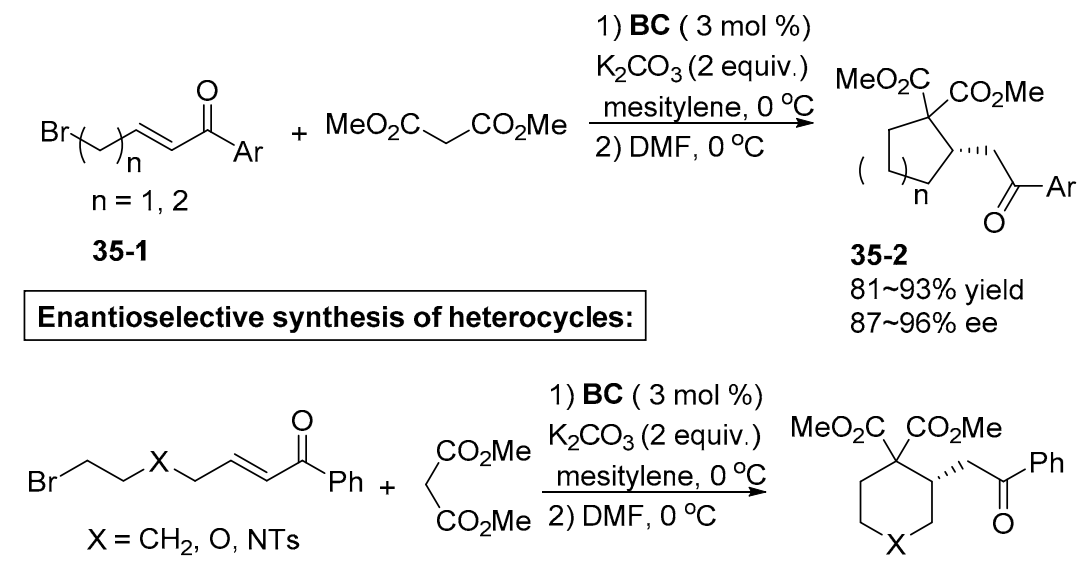

35-3

Useful transformations:
35-4: $\mathrm{X}=\mathrm{CH}_{2}, 95 \%$ yield, $95 \%$ ee

35-5: $X=O, 94 \%$ yield, $93 \%$ ee

35-6: $X=N T s, 90 \%$ yield, $82 \%$ ee

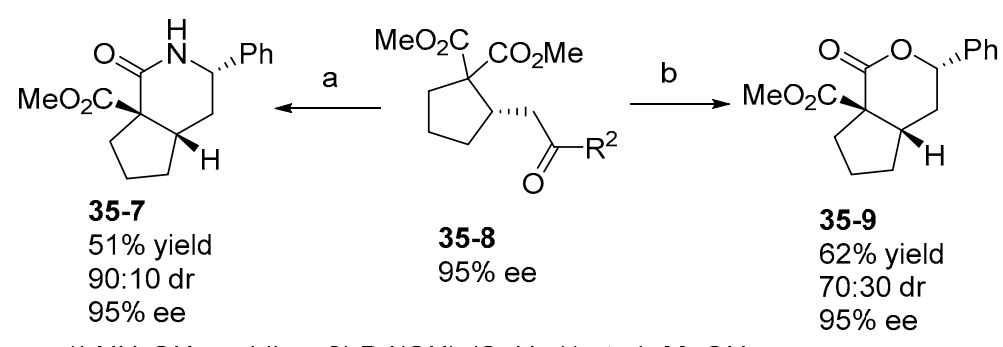

a: 1) $\mathrm{NH}_{2} \mathrm{OH}$, pyridine; 2) $\mathrm{Pd}(\mathrm{OH})_{2} / \mathrm{C}, \mathrm{H}_{2}$ (1 atm), $\mathrm{MeOH}$

b: 1) $\mathrm{NaBH}_{4}, \mathrm{MeOH}$; 2) TsOH, $\mathrm{CH}_{2} \mathrm{Cl}_{2}$

\section{The possible transition state:}

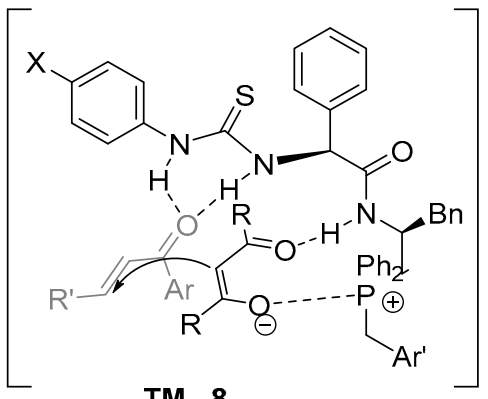

TM - 8

Scheme 35. Dipeptide-based phosphonium salts for asymmetric Michael addition $/ \mathrm{S}_{\mathrm{N}} 2$ sequence reaction. 
<smiles>[R]C=CC([R])=O</smiles>

36-1

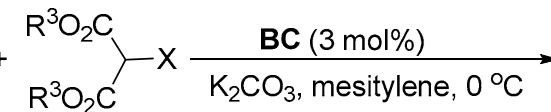

36-2<smiles>[R]OC([X])([R]O)C([R])CC([R])=O</smiles>

36-3

up to $99 \%$ yield up to $99 \%$ ee

Scheme 36. Asymmetric Michael addition reactions with malonates .<smiles>[R1]C=CC([R20])=O</smiles>

Scheme 37. Enantioselective tandem Michael/Michael addition reactions for chiral cyclopentanes.

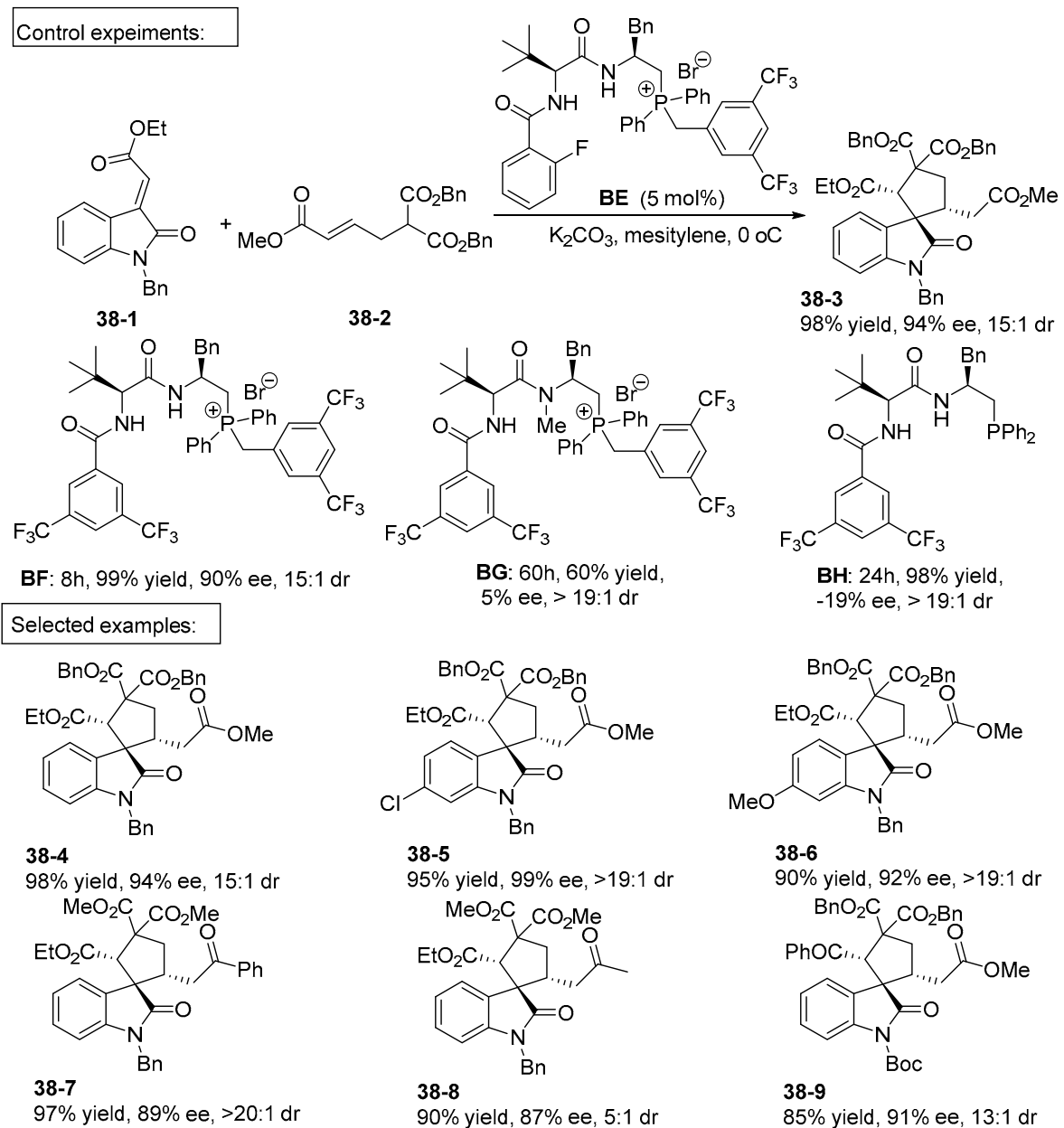

Scheme 38. Enantioselective tandem Michael/Michael addition reactions for spirocyclic oxindoles. 


\section{Derived from Cyclohexane}

1,2-trans-cyclohexanediamine, as a privileged chiral backbone, has been widely investigated in the design of novel catalysts for promoting asymmetric reactions $[63,64]$. For example, the Takemoto catalyst (thiourea-tertiary amine) has been widely applied in a large number of asymmetric reactions [65]. However, the chiral phase-transfer catalysts derived from 1,2-trans-cyclohexanediamine have been slowly developed when compared to other chiral backbones. Zhao and co-workers explored an asymmetric addition reaction between thiol and imine catalyzed thiourea-quaternary ammonium salts that were derived from 1,2-trans-cyclohexanediamine in 2013, but low enantioselectivity of the product was obtained [40]. Waser and co-workers successfully realized the asymmetric $\alpha$-fluorination ( $\alpha$-chlorination) of $\beta$-ketoesters yielding the chiral products with good enantioselectivities in the presence of the bifunctional (thio)urea-quaternary ammonium salts (Scheme 39) [66,67]. The biologically active isoindolinones can be efficiently synthesized, utilizing the bifunctional ammonium salts, for example, of the Belliotti (S)-PD172938 (Scheme 40) [68].

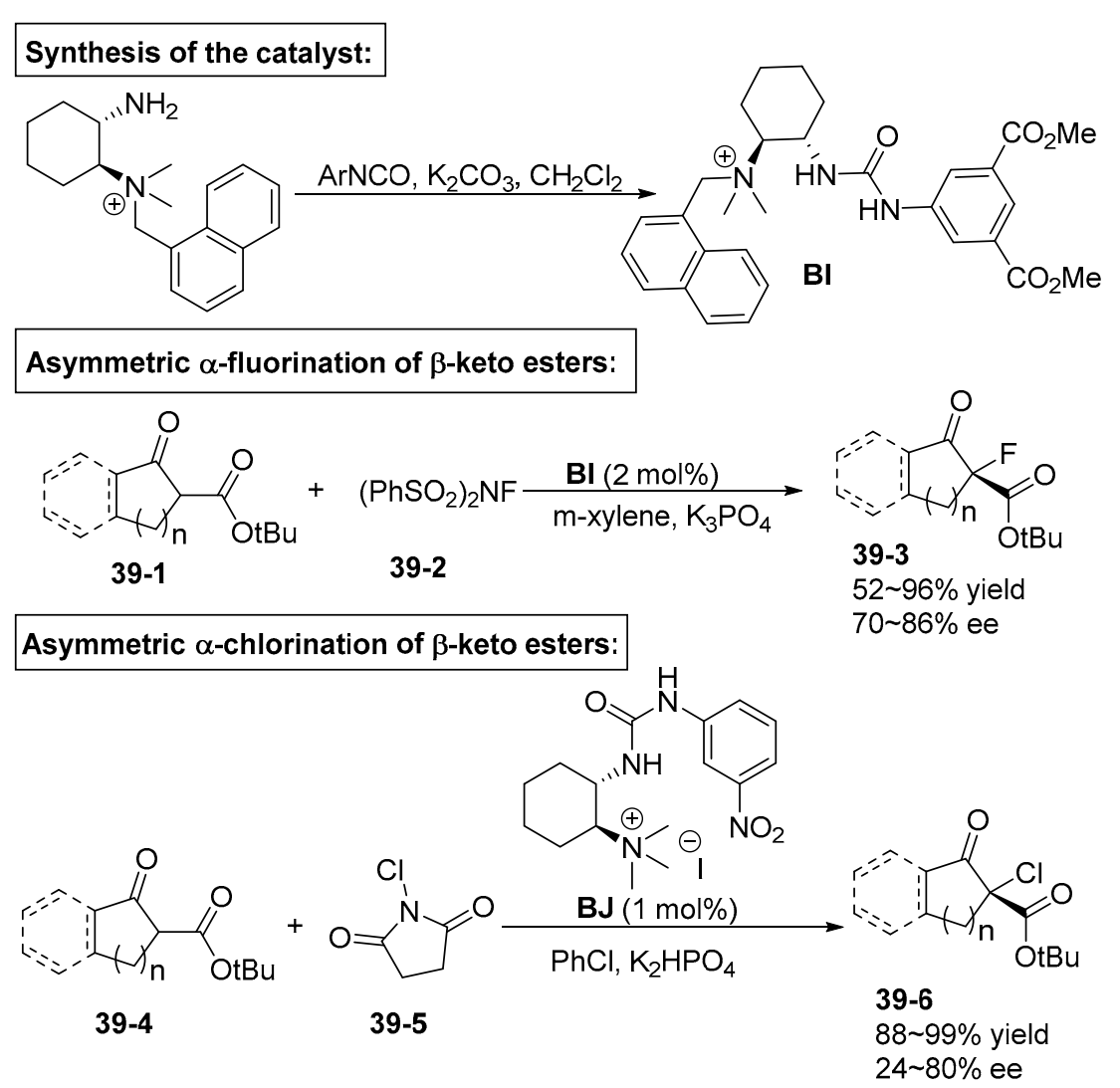

Scheme 39. Quaternary ammonium salts for asymmetric $\alpha$-fluorination ( $\alpha$-chlorination) of $\beta$-ketoesters. 


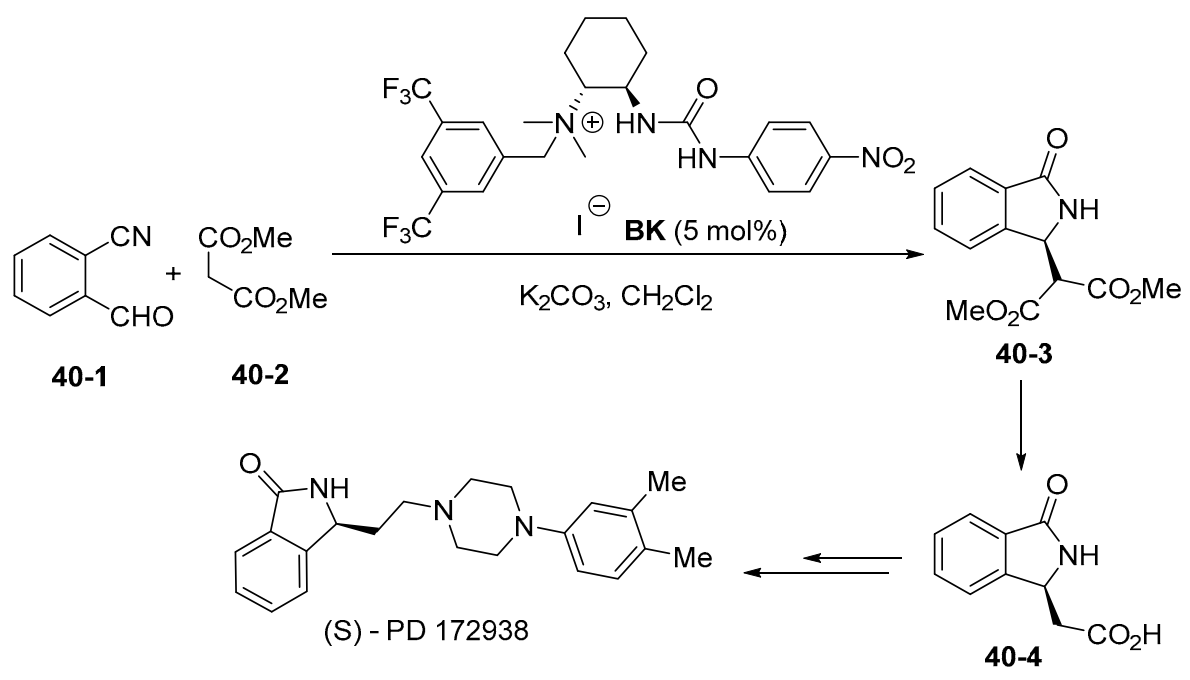

Scheme 40. The synthesis of chiral (S)-PD 172938.

Using oxaziridines as the electrophiles, Waser reported the asymmetric $\alpha$-hydroxylation reactions of $\beta$-ketoesters that were catalyzed by urea-quaternary ammonium salts under base-free conditions (Scheme 41) [69]. The reactions smoothly proceeded to yield $\alpha$-hydroxy- $\beta$-dicarbonyl products in high yields and ee values, irrespective of low ees for the acyclic $\alpha$-hydroxy- $\beta$-ketoester. The authors found that the enantioselectivity of the product increases with dilution, which was explained with the limited solubility of oxaziridine in MTBE (methyl tert-butyl ether). Meanwhile, a simultaneous kinetic resolution of the oxaziridine was observed. From the investigations on the mechanism by means of DFT calculations, the crucial importance of the hydrogen bonding interactions was illustrated in the transition model.

\section{Asymmetric $\alpha$-hydroxylation of $\beta$-ketoesters:}

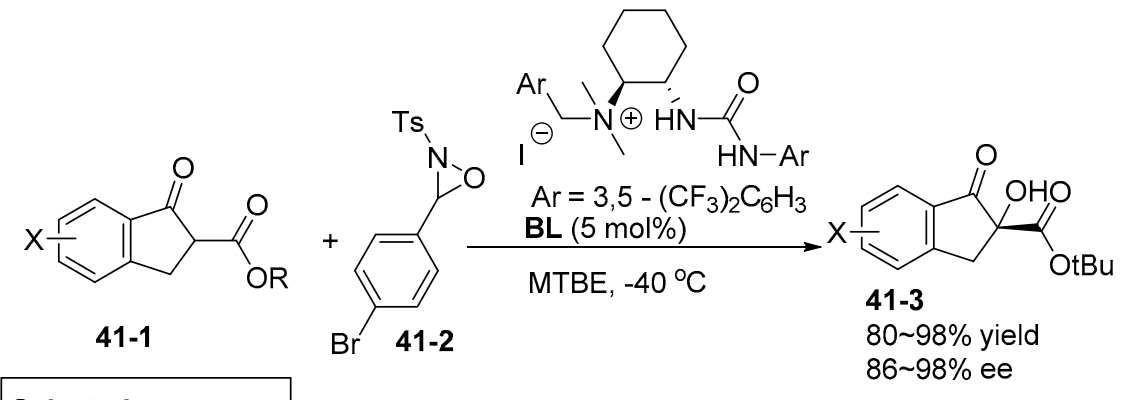

Selected examples:<smiles>CCCCC(=O)OC1(O)Cc2ccccc2C1=O</smiles>

$95 \%$ yield, $97 \%$ ee<smiles>CCOC(=O)C1(O)Cc2c(Br)ccc(OC)c2C1=O</smiles>

$87 \%$ yield, $98 \%$ ee<smiles>CCCOC(=O)C1(O)Cc2cc(F)ccc2C1=O</smiles>

41-3-2

$94 \%$ yield, $88 \%$ ee<smiles>CCCCC(=O)OC1(O)CCc2ccccc2C1=O</smiles>

41-3-5

$97 \%$ yield, $88 \%$ ee

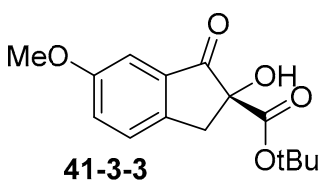

$80 \%$ yield, $86 \%$ ee<smiles>CCOC(=O)C(C)(O)C(=O)c1ccccc1</smiles>

41-3-6

$99 \%$ yield, $42 \%$ ee

Scheme 41. Asymmetric $\alpha$-hydroxylation reactions of $\beta$-ketoesters. 
Furthermore, Waser systematically investigated the bifunctional urea-quaternary ammonium salts for the asymmetric addition reactions of glycine imine to activated olefins by in 2015 (Scheme 42) [70]. This class of the chiral phase-transfer catalysts that were derived from 1,2-trans-cyclohexanediamine can be efficiently prepared in good yield via operationally simple sequences. Under the mild conditions, the chiral products can be obtained with good enantioselectivities, and the herein the aldol-initiated cascade reaction can also be performed furnishing the corresponding products with acceptable ee values.

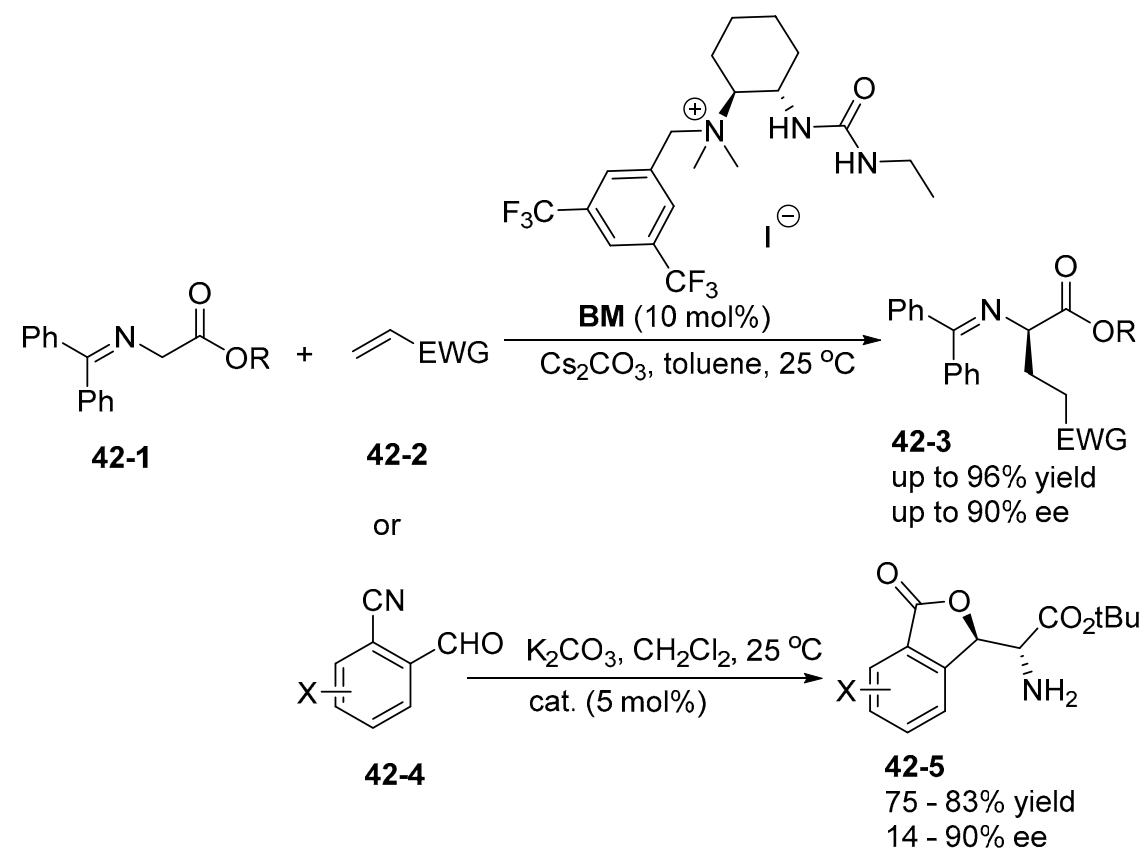

Scheme 42. Asymmetric addition reactions of glycine imine.

\section{Conclusions}

Over the past decades, asymmetric phase-transfer catalysis has proved its potential as an efficient strategy for preparing functional molecules, including biological compounds and pharmacies. Moreover, chiral phase-transfer catalysts with proton donating groups exhibited powerful capacity in improving the enantioselectivities and yields via the stabilization of the conformation and the activation of reactants, so the novel quaternary ammonium salts, quaternary phosphonium salts and tertiary sulfinium bearing the amide, (thio)-urea and squaramide groups have been successfully created in the recent years. With these novel chiral phase-transfer catalysts in hand, many novel asymmetric organic reactions were subsequently discovered and reported. However, mechanism research on the catalytic methods are highly demanded, which may accelerate the advance of this field. In addition, many challenges, as well as opportunities, still remain in this area. For example, these catalysts are limited to relatively activated substrates, so it will be a challenging project for realizing new reactions that cannot be achieved by the conventional catalysts. In addition, merging other catalytic strategies, such as visible light and transition metal catalysis, into the asymmetric phase-transfer catalysis utilizing the bifunctional catalysts with hydrogen bonds will expand the scope of the catalytic method in the future.

Author Contributions: The conceptualization, writing and editing were finished by H.W.

Funding: This research was funded by National Natural Science Foundation of China (21602125), Natural Science Foundation of Shandong Province (ZR2016BQ38) and China Postdoctoral Science Foundation (40411585).

Conflicts of Interest: The authors declare no conflict of interest. 


\section{References}

1. Starks, C.M. Phase-transfer catalysis. I. Heterogeneous reactions involving anion transfer by quaternary ammonium and phosphonium salts. J. Am. Chem. Soc. 1971, 93, 195-199. [CrossRef]

2. Maruoka, K. (Ed.) Asymmetric Phase Transfer Catalysis; Wiley: Weinheim, Germanny, 2008.

3. Ooi, T.; Maruoka, K. Recent advances in asymmetric phase-transfer catalysis. Angew. Chem. Int. Ed. 2007, 46, 4222-4266. [CrossRef] [PubMed]

4. Shirakawa, S.; Maruoka, K. Recent developments in asymmetric phase-transfer reactions. Angew. Chem. Int. Ed. 2013, 52, 4312-4348. [CrossRef] [PubMed]

5. Novacek, J.; Waser, M. Bifunctional Chiral Quaternary Ammonium Salt Catalysts: A Rapidly Emerging Class of Powerful Asymmetric Catalysts. Eur. J. Org. Chem. 2013, 2013, 637-648. [CrossRef]

6. Kaneko, S.; Kumatabara, Y.; Shirakawa, S. A new generation of chiral phase-transfer catalysis. Org. Biomol. Chem. 2016, 14, 5367-5376. [CrossRef] [PubMed]

7. Liu, S.; Kumatabara, Y.; Shirakawa, S. Chiral quaternary phosphonium salts as phase-transfer catalysts for environmentally benign asymmetric transformations. Green Chem. 2016, 18, 331-341. [CrossRef]

8. Golandaj, A.; Ahmad, A.; Ramjugernath, D. Phosphonium Salts in Asymmetric Catalysis: A Journey in a Decade's Extensive Research Work. Adv. Synth. Catal. 2017, 359, 3676-3706. [CrossRef]

9. Schörgenhumer, J.; Tiffner, M.; Waser, M. Chiral phase-transfer catalysis in the asymmetric $\alpha$-heterofunctionalization of prochiral nucleophiles. Beilstein J. Org. Chem. 2017, 13, 1753-1769. [CrossRef] [PubMed]

10. Tan, J.; Yasuda, N. Contemporary asymmetric phase transfer catalysis: Large-scale industrial applications. Org. Process Res. Dev. 2015, 19, 1731-1746. [CrossRef]

11. Gururaja, G.; Waser, M. Asymmetric phase-transfer catalysis as a powerful tool in the synthesis of biologically active chiral complex natural products. Stud. Nat. Prod. Chem. 2014, 43, 409-435.

12. Shirakawa, S.; Maruoka, K. Chiral onium salts (Phase-transfer reactions). Compr. Enant. Organocatalysis 2013, $2,365-379$.

13. Shirakawa, S.; Moteki, S.A.; Maruoka, K. Asymmetric phase-transfer catalysis. In Modern Tools for the Synthesis of Complex Bioactive Molecules; John Wiley \& Sons. Inc.: Hoboken, NJ, USA, 2012; pp. 213-242.

14. Ager, D. Alkaloid derived auxiliaries: Cinchona alkaloid and derivatives. Compr. Chirality 2012, 3, $223-247$.

15. Brak, K.; Jacobsen, E.N. Asymmetric ion-pairing catalysis. Angew. Chem. Int. Ed. 2013, 52, 534-561. [CrossRef] [PubMed]

16. Doyle, A.G.; Jacobsen, E.N. Small-molecule H-bond donors in asymmetric catalysis. Chem. Rev. 2007, 107, 5713-5743. [CrossRef] [PubMed]

17. Fiaud, J.-C. Asymmetric alkylation reaction by means of a chiral phase transfer catalyst. Tetrahedron Lett. 1975, 16, 3495-3496. [CrossRef]

18. Gomez-Bengoa, E.; Linden, A.; López, R.; Múgica-Mendiola, I.; Oiarbide, M.; Palomo, C. Asymmetric aza-Henry reaction under phase transfer catalysis: An experimental and theoretical study. J. Am. Chem. Soc. 2008, 130, 7955-7966. [CrossRef] [PubMed]

19. Bernal, P.; Fernández, R.; Lassaletta, J.M. Organocatalytic asymmetric cyanosilylation of nitroalkenes. Chem. Eur. J. 2010, 16, 7714-7718. [CrossRef] [PubMed]

20. Johnson, K.M.; Rattley, M.S.; Sladojevich, F.; Barber, D.M.; Nuñez, M.G.; Goldys, A.M.; Dixon, D.J. A new family of cinchona-derived bifunctional asymmetric phase-transfer catalysts: Applications to the enantioand diastereoselective nitro-Mannich reaction of amidosulfones. Org. Lett. 2012, 14, 2492-2495. [CrossRef] [PubMed]

21. Li, M.; Woods, P.A.; Smith, M.D. Cation-directed enantioselective synthesis of quaternary-substituted indolenines. Chem. Sci. 2013, 4, 2907-2911. [CrossRef]

22. Wang, B.; Xu, T.; Zhu, L.; Lan, Y.; Wang, J.; Lu, N.; Wei, Z.; Lin, Y.; Duan, H. Highly enantioselective nitro-Mannich reaction of ketimines under phase-transfer catalysis. Org. Chem. Front. 2017, 4, 1266-1271. [CrossRef]

23. Sorrentino, E.; Connon, S.J. Enantioselective Alkylative Kinetic Resolution of 2-Oxindole-Derived Enolates Promoted by Bifunctional Phase Transfer Catalysts. Org. Lett. 2016, 18, 5204-5207. [CrossRef] [PubMed] 
24. Wang, B.; Liu, Y.; Sun, C.; Wei, Z.; Cao, J.; Liang, D.; Lin, Y.; Duan, H. Asymmetric Phase-Transfer Catalysts Bearing Multiple Hydrogen-Bonding Donors: Highly Efficient Catalysts for Enantio- and Diastereoselective Nitro-Mannich Reaction of Amidosulfones. Org. Lett. 2014, 16, 6432-6435. [CrossRef] [PubMed]

25. Lu, N.; Li, R.; Wei, Z.; Cao, J.; Liang, D.; Lin, Y.; Duan, H.J. Enantio- and Diastereoselective Nitro-Mannich Reaction of $\alpha$-Aryl Nitromethanes with Amidosulfones Catalyzed by Phase-Transfer Catalysts. Org. Chem. 2017, 82, 4668-4676. [CrossRef] [PubMed]

26. Shirakawa, S.; Atsuyuki, K.; Tokuda, T.; Maruoka, K. Efficient approach for the design of effective chiral quaternary phosphonium salts in asymmetric conjugate additions. Chem. Sci. 2013, 4, 2248-2252. [CrossRef]

27. Shirakawa, S.; Tokashi, T.; Kasai, A.; Maruoka, K. Design of chiral bifunctional quaternary phosphonium bromide catalysts possessing an amide moiety. Org. Lett. 2013, 15, 3350-3353. [CrossRef] [PubMed]

28. Shirakawa, S.; Koga, K.; Tokuda, T.; Yamamoto, K.; Maruoka, K. Catalytic asymmetric synthesis of 3,3'-diaryloxindoles as triarymethanes with a chiral all-carbon quaternary center: Phase-transfer-catalyzed $\mathrm{S}_{\mathrm{N}}$ Ar reaction. Angew. Chem. Int. Ed. 2014, 53, 6220-6223. [CrossRef] [PubMed]

29. Liu, S.; Maruoka, K.; Shirakawa, S. Chiral tertiary sulfonium salts as effective catalysts for asymmetric base-free neutral phase-transfer reactions. Angew. Chem. Int. Ed. 2017, 56, 4819-4923. [CrossRef] [PubMed]

30. Hughes, A.B. (Ed.) Amino Acids, Peptides and Proteins in Organic Chemistry: Modified Amino Acids, Oranocatalysis and Enzymes; Wiely: Weinheim, Germanny, 2011; Volume 2.

31. Chai, Z.; Zhao, G. Efficient organocatalysts derived from simple chiral acyclic amino acids in asymmetric catalysis. Catal. Sci. Technol. 2012, 2, 29-41. [CrossRef]

32. Xu, L.-W.; Lu, Y. Primary amino acids: Privileged catalysts in enantioselective organocatalysis. Org. Biomol. Chem. 2008, 6, 2047-2053. [CrossRef] [PubMed]

33. Ohmatsu, K.; Kiyokawa, M.; Ooi, T. Chiral 1,2,3-triazoliums as new cationic organic catalysts with anion-recognition ability: Application to asymmetric alkylation of oxindoles. J. Am. Chem. Soc. 2011, 133, 1307-1309. [CrossRef] [PubMed]

34. Ohmatsu, K.; Hamajima, Y.; Ooi, T. Catalytic asymmetric ring opening of meso an dterminal aziridines with halides mediated by chiral 1,2,3-triazolium silicates. J. Am. Chem. Soc. 2012, 134, 8794-8797. [CrossRef] [PubMed]

35. Ohmatsu, K.; Ando, Y.; Ooi, T. Asymmetric Substitution at the Tetrasubstituted Chiral Carbon: Catalytic Ring-Opening Alkylation of Racemic 2,2-Disubstituted Aziridines with 3-Substituted Oxindoles. J. Am. Chem. Soc. 2013, 135, 18706-18709. [CrossRef] [PubMed]

36. Ohmatsu, K.; Goto, A.; Ooi, T. Catalytic asymmetric Mannich-type reactions of $\alpha$-cyano $\alpha$-sulfonyl carbanions. Chem. Commun. 2012, 48, 7913-7915. [CrossRef] [PubMed]

37. Ohmatsu, K.; Ando, Y.; Nakashima, T.; Ooi, T. A Modular Strategy for the Direct Catalytic Asymmetric a-Amination of Carbonyl Compounds. Chem 2016, 1, 802-810. [CrossRef]

38. Ohmatsu, K.; Ando, Y.; Ooi, T. In Situ Electrophilic Activation of Hydrogen Peroxide for Catalytic Asymmetric $\alpha$-Hydroxylation of 3-Substituted Oxindoles. Synlett 2017, 28, 1291-1294.

39. Wang, H.-Y.; Chai, Z.; Zhao, G. Novel bifunctional thioureaeammonium salt catalysts derived from amino acids: Application to highly enantio- and diastereoselective aza-Henry reaction. Tetrahedron 2013, 69, 5104-5111. [CrossRef]

40. Wang, H.-Y.; Zhang, J.-X.; Cao, D.-D.; Zhao, G. Enantioselective Addition of Thiols to Imines Catalyzed by Thiourea-Quaternary Ammonium Salts. ACS Catal. 2013, 3, 2218-2221. [CrossRef]

41. Zhang, J.-X.; Wang, H.-Y.; Jin, Q.-W.; Zheng, C.-W.; Zhao, G.; Shang, Y.-J. Thiourea-quaternary ammonium salt catalyzed asymmetric 1,3-dipolar cycloaddition of imino esters to construct spiro [pyrrolidin-3,3'-oxindoles]. Org. Lett. 2016, 18, 4774-4777. [CrossRef] [PubMed]

42. Du, T.; Li, Z.; Zheng, C.; Fang, G.; Yu, L.; Liu, J.; Zhao, G. Highly enantioselective 1,3-dipolar cycloaddition of imino esters with benzofuranone derivatives catalyzed by thiourea-quaternary ammonium salt. Tetrahedron 2018, 74, 7485-7494. [CrossRef]

43. Coppola, G.M.; Schuster, H.F. (Eds.) $\alpha$-Hydroxy Acids in Enantioselective Synthesis; Wiely: Weinheim, Germany, 1997.

44. Duan, S.; Li, S.; Ye, X.; Du, N.-N.; Tan, C.-H.; Jiang, Z. Enantioselective Synthesis of Dialkylated $\alpha$-Hydroxy Carboxylic Acids through Asymmetric Phase-Transfer Catalysis. J. Org. Chem. 2015, 80, 7770-7778. [CrossRef] [PubMed] 
45. Jin, Q.; Zheng, C.; Zhao, G.; Zou, G. Bifunctional quaternary ammonium salts catalyzed stereoselective conjugate addition of oxindoles to electron-deficient $\beta$-haloalkenes. J. Org. Chem. 2017, 82, 4840-4850. [CrossRef] [PubMed]

46. Cao, D.; Chai, Z.; Zhang, J.; Ye, Z.; Xiao, H.; Wang, H.; Chen, J.; Wu, X.; Zhao, G. Thiourea-phosphonium salts from amino acids: Cooperative phase-transfer catalysts in the enantioselective aza-Henry reaction. Chem. Commun. 2013, 49, 5972-5974. [CrossRef] [PubMed]

47. Wang, H.; Wang, K.; Ren, Y.; Li, N.; Tang, B.; Zhao, G. Asymmetric Strecker reactions catalyzed by thiourea phosphonium and ammonium salts. Adv. Synth. Catal. 2017, 359, 1819-1824. [CrossRef]

48. Wu, X.-Y.; Liu, Q.; Liu, Y.; Wang, Q.; Zhang, Y.; Chen, J.; Cao, W.; Zhao, G. Amino acid-derived phosphonium salts-catalyzed Michael addition of 3-substituted oxindoles. Adv. Synth. Catal. 2013, 355, 2701-2706. [CrossRef]

49. Chu, W.-D.; Zhang, L.-F.; Bao, X.; Zhao, X.-H.; Zeng, C.; Du, J.-Y.; Zhang, G.-B.; Wang, F.-X.; Ma, X.-Y.; Fan, C.-A. Asymmetric catalytic 1,6-conjugate addition /aromatization of para-quinone methides: Enantioselective introduction of functionalized diarylmethine stereogenic centers. Angew. Chem. Int. Ed. 2013, 52, 9229-9233. [CrossRef] [PubMed]

50. Ge, L.; Lu, X.; Cheng, C.; Chen, J.; Cao, W.; Wu, X.; Zhao, G. Amide-Phosphonium Salt as Bifunctional Phase Transfer Catalyst for Asymmetric 1,6-Addition of Malonate Esters to para-Quinone Methides. J. Org. Chem. 2016, 81, 9315-9325. [CrossRef] [PubMed]

51. Cheng, C.; Lu, X.; Ge, L.; Chen, J.; Cao, W.; Wu, X.; Zhao, G. Effective asymmetric vinylogous Mannich reaction of isatin imines with $\alpha, \alpha$-dicyanoolefins in the presence of a simple chiral amide phosphonium bifunctional phase transfer catalyst. Org. Chem. Front. 2017, 4, 101-114. [CrossRef]

52. Wen, S.; Li, X.; Lu, Y. Enantioselective alkylation of glycine imine promoted by amino-acid-derived phosphonium salts. Asian J. Org. Chem. 2016, 5, 1457-1460. [CrossRef]

53. Zhang, J.; Cao, D.; Wang, H.; Zhao, G.; Shang, Y. Enantioselective desymmetrization of meso-aziridines with aromatic thiols catalyzed by chiral bifunctional quaternary phosphonium salts derived from $\alpha$-amino acids. Tetrahedron 2015, 71, 1785-1791. [CrossRef]

54. Pan, R.; Zhang, J.; Zheng, C.; Wang, H.; Cao, D.; Cao, W.; Zhao, G. Enantioselective direct Mannich reaction of functionalized acetonitrile to N-Boc imines catalyzed by quaternary phosphonium catalysis. Tetrahedron 2017, 73, 2349-2358. [CrossRef]

55. Wen, S.; Li, X.; Yao, W.; Waheed, A.; Ullah, N.; Lu, Y. Highly enantioselective conjugate addition of glycine imines to activated alkenes catalyzed by amino-acid-derived chiral phosphonium salts. Eur. J. Org. Chem. 2016, 2016, 4298-4301. [CrossRef]

56. Cao, D.; Zhang, J.; Wang, H.; Zhao, G. Dipeptide-Derived Multifunctional Quaternary Phosphonium Salt Catalyzed Asymmetric Cyclizations via a Tandem Michael Addition/ $\mathrm{S}_{\mathrm{N}} 2$ Sequence. Chem. Eur. J. 2015, 21, 9998-10002. [CrossRef] [PubMed]

57. Moyano, A.; Rios, R. Asymmetric organocatalytic cyclization and cycloaddition reactions. Chem. Rev. 2011, 111, 4703-4832. [CrossRef] [PubMed]

58. Volla, C.M.R.; Atodiresei, I.; Rurping, M. Catalytic C-C bond-forming multi-component cascade or domino reactions: Pushing the boundaries of complexity in asymmetric organocatalysis. Chem. Rev. 2014, 114, 2390-2431. [CrossRef] [PubMed]

59. Wang, Y.; Lu, H.; Xu, P.-F. Asymmetric catalytic cascade reactions for constructing diverse scaffolds and complex molecules. Acc. Chem. Res. 2015, 48, 1832-1844. [CrossRef] [PubMed]

60. Cao, D.; Fang, G.; Zhang, J.; Wang, H.; Zheng, C.; Zhao, G. Enantioselective Michael Addition of Malonates to Chalcone Derivatives Catalyzed by Dipeptide-derived Multifunctional Phosphonium Salts. J. Org. Chem. 2016, 81, 9973-9982. [CrossRef] [PubMed]

61. Lu, Y.; Cao, D.; Zhang, J.; Wang, H.; Zou, G.; Zhao, G. Dipeptide-derived multifunctional phosphonium salt as a catalyst to synthesize highly functionalized chiral cyclopentanes. Tetrahedron 2016, 72, 4141-4150. [CrossRef]

62. Zhang, J.; Cao, D.; Wang, H.; Zheng, C.; Zhao, G.; Shang, Y. Enantioselective Construction of Spirocyclic Oxindoles via Tandem Michael/Michael Reactions Catalyzed by Multifunctional Quaternary Phosphonium Salt. J. Org. Chem. 2016, 81, 10558-10568. [CrossRef] [PubMed] 
63. Bennani, Y.L.; Hanessian, S. Trans-1,2-Diaminocyclohexane Derivatives as Chiral Reagents, Scaffolds, and Ligands for Catalysis: Applications in Asymmetric Synthesis and Molecular Recognition. Chem. Rev. 1997, 97, 3161-3196. [CrossRef] [PubMed]

64. Kizirian, J.-C. Chiral tertiary diamine in asymmetric synthesis. Chem. Rev. 2008, 108, 140-205. [CrossRef] [PubMed]

65. Okino, T.; Hoashi, Y.; Takemoto, Y.J. Enantioselective Michael reaction of malonates to nitroolefins catalyzed by bifunctional organocatalysts. J. Am. Chem. Soc. 2003, 125, 12672-12673. [CrossRef] [PubMed]

66. Novacek, J.; Waser, M. Syntheses and Applications of (Thio)Urea-Containing Chiral Quaternary Ammonium Salt Catalysts. Eur. J. Org. Chem. 2014, 2014, 802-809. [CrossRef] [PubMed]

67. Novacek, J.; Monkowius, U.; Himmelsbach, M.; Waser, M. Asymmetric $\alpha$-chlorination of $\beta$-ketoesters using bifunctional ammonium salt catalysis. Monatsh. Chem. 2016, 147, 533-538. [CrossRef]

68. Mola, A.D.; Tiffner, M.; Scorzelli, F.; Palombi, L.; Filosa, R.; Caprariis, P.D.; Waser, M.; Massa, A. Bifunctional phase-transfer catalysis in the asymmetric synthesis of biologically active isoindolinones. Beilstein J. Org. Chem. 2015, 11, 2591-2599. [CrossRef] [PubMed]

69. Novacek, J.; Izzo, J.A.; Vetticatt, M.J.; Waser, M. Bifunctional Ammonium Salt Catalyzed Asymmetric $\alpha$-Hydroxylation of $\beta$-Ketoesters by Simultaneous Resolution of Oxaziridines. Chem. Eur. J. 2016, 22, 17339-17344. [CrossRef] [PubMed]

70. Tiffner, M.; Novacek, J.; Busillo, A.; Gratzer, K.; Massa, A.; Waser, M. Design of chiral urea-quaternary ammonium salt hybrid catalysts for asymmetric reactions of glycine Schiff bases. RSC Adv. 2015, 5, 78941-78949. [CrossRef] [PubMed]

(C) 2019 by the author. Licensee MDPI, Basel, Switzerland. This article is an open access article distributed under the terms and conditions of the Creative Commons Attribution (CC BY) license (http:/ / creativecommons.org/licenses/by/4.0/). 